
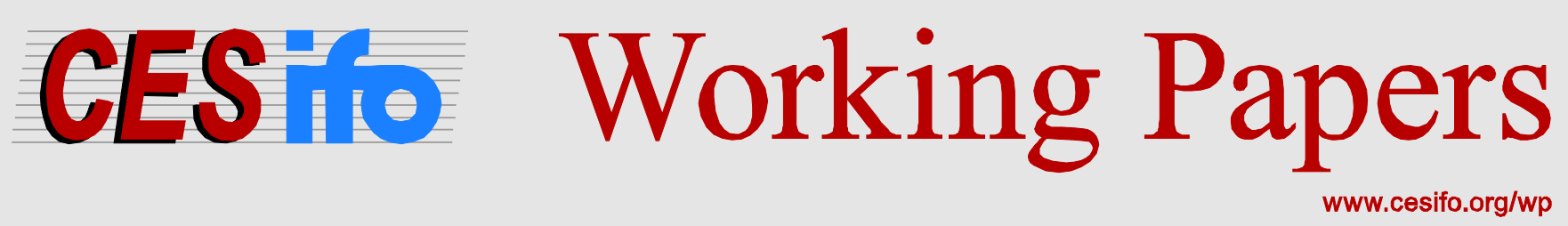

\title{
Parent-Child Information Frictions and Human Capital Investment: Evidence from a Field Experiment
}

\author{
Peter Bergman
}

CESIFO WORKING PAPER NO. 5391

CATEGORY 5: ECONOMICS OF EDUCATION

JUNE 2015

An electronic version of the paper may be downloaded

- from the SSRN website:

- from the RePEc website:

- from the CESifo website:

wWw.SSRN.com

www.RePEc.org

www.CESifo-group.org/wp 


\title{
Parent-Child Information Frictions and Human Capital Investment: Evidence from a Field Experiment
}

\begin{abstract}
This paper uses a field experiment to answer how information frictions between parents and their children affect investments in education and how much reducing these frictions can improve student achievement. In Los Angeles, a random sample of parents was provided detailed information about their child's academic progress. I frame the results in the context of a persuasion game between parents and their children. Parents have upwardly-biased beliefs about their child's effort and the information treatment reduces this bias while increasing parental monitoring. More information allows parents to induce more effort from their children, which translates into significant gains in achievement. Relative to other interventions, additional information to parents potentially produces gains in achievement at a low cost.
\end{abstract}

JEL-Code: I200, I210, I240.

Keywords: information frictions, experiment, parents.

\author{
Peter Bergman \\ Teachers College \\ Columbia University \\ 525 W. $120^{\text {th }}$ Street \\ USA - New York, NY 10027 \\ bergman@tc.columbia.edu
}

I am extremely grateful to Adriana Lleras-Muney, Pascaline Dupas and Karen Quartz for their advice and support. Andrew Kosenko and Chaoyan Zhu provided excellent research assistance. I thank the editor and four referees for their detailed comments, as well Sandra Black, PierreAndré Chiappori, Jon Guryan, Navin Kartik, Day Manoli, Magne Mogstad, Paco Martorell, Sarah Reber, Todd Rogers, Mitchell Wong for their feedback. I also thank seminar participants at AEFP, Case Western University, CESifo, the CFPB, Mathematica, NBER Education meeting, RAND, Teachers College, Columbia University, UC Berkeley, the University of Chicago Becker Friedman Institute and UCLA for their comments and suggestions. All errors are my own. 


\section{Introduction}

Numerous papers reinforce the importance of parental investments in their child's human capital, and in turn, long-run economic outcomes (e.g. Cunha et al., 2006; Houtenville and Smith Conway, 2007; Todd and Wolpin, 2007). However, most models of human capital investment do not incorporate information frictions between parents and their children $L^{1}$ Children may wish to hide information from their parents about their human capital investment due to higher discount rates or difficulty planning for the future (Bettinger and Slonim, 2007; Steinberg et al., 2009; Levitt, List, Neckermann and Sadoff, 2011). If children disclose information strategically, ill-informed parents may have imperfect knowledge about their child's effort in school that impedes human capital investments. This paper uses a field experiment to answer how information frictions between parents and their children affects these investments and how much reducing these frictions can improve student achievement.

At the outset, it is uncertain whether reducing these information frictions can facilitate educational investments or improve outcomes. On the one hand, there is an association between the quality of information schools provide and school performance. In schools where most students go on to college, $83 \%$ of parents are satisfied with the school's ability to communicate information about their child's academic performance, but in schools where most students do not go on to college, $43 \%$ of the parents are satisfied with this communication (Civic Enterprises, 2004). One the other hand, previous research has questioned the efficacy of parental monitoring. Widely-cited work by Kerr and Stattin (2000) argues that voluntarychild disclosure generates positive student behaviors while parental monitoring causes worse behaviors.

However, these associations cannot be interpreted as causal; parent and child behaviors are endogenously determined. Parents may monitor because their child is doing poorly. Moreover, children may be more likely to disclose if they are already performing well. I model

\footnotetext{
${ }^{1}$ Several important exceptions in the context of human-capital investment are Weinberg (2001), Berry (2009), and Bursztyn and Coffman (2012).
} 
the interaction between parents and their children as a persuasion game with monitoring and incentives. This model generates several testable implications. Parents of lower-performing children are relatively more uncertain about their child's performance than parents of higherperforming children. Parents with upwardly biased beliefs will have children who exert less effort in school, ceteris paribus. Intuitively, higher monitoring costs imply lower student effort as well. Similar to previous literature, parental monitoring and voluntary child disclosure would be negatively and positively associated with child effort, respectively. In contrast however, simple comparative statics show a theoretical reduction in monitoring costs or a reduction in upwardly biased beliefs would increase student effort.

To measure the causal effect of reducing these frictions on human capital investments and achievement, I conducted an experiment at a school in a low-income area of Los Angeles. Out of all 462 students in grades six through eleven, 242 students' parents or guardians were randomly selected to receive additional information about their child's academic progress. This information consisted of emails, text messages and phone calls listing students' missing assignments and grades several times a month over a six-month period. The information provided was detailed. Messages contained the class, assignment names, problems and page numbers of the missing work whenever possible. Course grades were sent to families every five to eight weeks. To quantify the effects on student effort, achievement and parental investments, I gathered administrative data on assignment completion, work habits, cooperation, attendance and test scores. Parent and student surveys were conducted immediately after the school year ended to provide additional data about each family's response.

The results for high school students suggest there are significant information frictions. First, parents have biased beliefs about their child's effort in school: when asked to estimate how many assignments their child has missed in math class, parents vastly understate. The size of this bias is negatively and significantly associated with student achievement and the information treatment attenuates this bias. Second, more information increases the intensity of parental monitoring and incentives and increases inputs such as student effort. 
These effects coincide with an increase in parental monitoring about their child's academic progress. Parents in the treatment group contacted the school about this information $83 \%$ more often than the control group and parent-teacher conference attendance increased by $53 \%$. Unfortunately, the middle-school teachers replicated the treatment for all students in their grades, contaminating the results for those families. There are no estimated effects on middle school parent or student outcomes.

In terms of achievement, reducing these information problems can potentially produce gains on par with education reforms such as high-quality charter schools. For high school students, GPA increased by .19 standard deviations. There is evidence that test scores for math increased by .21 standard deviations, though there was no gain for English scores (.04 standard deviations). These effects are driven by several changes in students' inputs: assignment completion increased by $25 \%$ and the likelihood of unsatisfactory work habits and cooperation decreased by $24 \%$ and $25 \%$, respectively. Classes missed by students decreased by $28 \%$. For comparison, the Harlem Children's Zone increased math scores and English scores by .23 and .05 standard deviations and KIPP Lynn charter schools increased these scores .35 and .12 standard deviations (Dobbie and Fryer, 2010; Angrist et al., 2010).

Interestingly, teachers had little insight regarding for whom this intervention would be particularly effective. I asked teachers to predict which families they thought would benefit the most from the additional information, but there were no differential effects for the families they selected.

Relative to other interventions, providing information could be a cost effective way to address sub-optimal student effort and improve student achievement. ${ }^{2}$ Interventions aimed at adolescents' achievement are often costly because they rely on financial incentives, either for teachers (Springer et al., 2010; Fryer, 2011), for students (Angrist and Lavy, 2002; Bettinger, 2008; Fryer, 2011) or for parents (Miller, Riccio and Smith, 2010). Providing financial

\footnotetext{
${ }^{2}$ Examples of other information-based interventions in education include providing families information describing student achievement at surrounding schools (Hastings and Weinstein, 2008; Andrabi, Das and Khwaja 2009), parent outreach programs (Avvisati et al., 2010), providing principals information on teacher effectiveness (Rockoff et al., 2010) and helping parents fill out financial aid forms (Bettinger et al., 2009).
} 
incentives for high school students cost $\$ 538$ per .10 standard-deviation increase, excluding administrative costs (Fryer, 2011). If teachers were to provide additional information to parents as in this study, the cost per student per .10 standard-deviation increase in GPA or math scores would be $\$ 156$ per child per year. Automated messages could reduce this cost further.

These costs raise an important related question, which is how much parents might be willing to pay to reduce these information problems. This study does not address this question, but Bursztyn and Coffman (2012) use a lab experiment with low-income families in Brazil to show parents are willing to pay substantial amounts of money for information on their child's attendance.

While this paper shows that an intensive information-to-parents service potentially can produce gains to student effort and achievement, its policy relevance depends on how well it translates to other contexts and scales up. Large school districts such as Los Angeles, Chicago, and Baltimore have purchased systems that make it easier for teachers to improve communication with parents by posting grades online, sending automated emails regarding grades, or text messaging parents regarding schoolwork. The availability of these services prompts questions about their usage, whether teachers update their grade books often enough to provide information, and parental demand for this information. This paper discusses but does not address these questions empirically.

The rest of the paper proceeds as follows. Sections II presents the theoretical framework. Sections III and IV describe the experimental design and the estimation strategy. Sections V and VI show the results and mechanisms for the high school students, respectively. Section VII summarizes the results for middle school students and Section VIII concludes with a discussion of external validity and cost-effectiveness. 


\section{Theoretical Framework}

I model the interaction between parents and their children as one of strategic-information disclosure, or a persuasion game (Dye, 1985; Shin, 1994), with parental monitoring and incentives. While I focus on information, parental beliefs, and monitoring costs, several papers model the parent-child interaction as a non-cooperative game: Akabayashi, (2005); Bursztyn and Coffman (2012); Cosconati, (2009); Hotz et al., (2008); and Weinberg, (2001).

The actions and parameters are as follows. Children choose to exert effort $(E)$ in school or shirk $(S)$. If available, children may also disclose $(D)$ verifiable reports to parents regarding their effort - for instance graded papers or report cards - or choose to hide this information $(N D)$. Disclosure is costless. Effort in school is costly to the child but is less costly to high $(H)$ types than low $(L)$ types $\left(c_{H}<c_{L}\right)$. Parents value their child's effort as $V$ and assign zero value to no effort. Parents have beliefs their child is a high type with probability $\pi$ and whether or not a verifiable report exists with probability $R$. The latter breaks the "unraveling result" (Grossman, 1981; Milgrom, 1981), in which a parent simply assumes the worst about their child's effort in the absence of information disclosure, and is particularly pertinent to low-achieving schools in which parents report school communication is often poor (Civic Enterprises, 2004). Parents may monitor $(M)$ effort at cost $m$, for example by going to the school to speak with teachers, and parents take away privileges $w$ if children exert inadequate effort with respect to parental preferences. Parents may only take away privileges if the child discloses an unsatisfactory report or the parent obtains one via monitoring. The timing is as follows. (1) Nature draws the child's type, high or low. (2) The child observes their own type and then chooses to exert effort in school or to shirk. (3) The school gives out a report or not. Reports are verifiable, and if drawn, document whether the child has worked or shirked. (4) The child observes if a report exists and chooses whether to disclose this report to his or her parents or not. (5) Finally, the parent observes whether the child discloses a report and then decides whether to monitor (and obtain a verifiable report) or 
not to monitor.

Conditional payoffs for a child of type $i$ are as follows:

$$
U_{i}= \begin{cases}w-c_{i} & \text { if } E=1 \text { for } M \in\{0,1\} \\ w & \text { if } E=0 \text { and } M=0 \\ 0 & \text { if } E=0 \text { and } M=1\end{cases}
$$

Conditional payoffs for parents are as follows: ${ }^{3}$

$$
U_{p}= \begin{cases}V-w & \text { if } M=0 \text { and } E=1 \\ V-w-m & \text { if } M=1 \text { and } E=1 \\ -m & \text { if } M=1 \text { and } E=0 \\ -w & \text { if } M=0 \text { and } E=0\end{cases}
$$

To illustrate how strategic information disclosure and imperfect school-parent communication affects this game, consider parents' posterior beliefs if their child plays the strategy work and disclose if there exists a report conditional on being high type and shirk and do not disclose regardless of whether a report exists conditional on being low type. The following is parents' posterior belief their child is a high type conditional on the child not disclosing any information.

$$
\operatorname{Pr}(H \mid N D)=\frac{\operatorname{Pr}(N D \mid H) \operatorname{Pr}(H)}{\operatorname{Pr}(N D \mid H) \operatorname{Pr}(H)+\operatorname{Pr}(N D \mid L) \operatorname{Pr}(L)}=\frac{(1-R) \pi}{1-R \pi}
$$

It is straightforward to see that as parents become more certain that the school has provided a report (the probability of $R$ increases), parents become more certain their child is of low type if they did not disclose this information. If school reporting is infrequent or parents are unaware of school reports, parents can no longer discern low type from a lack of school

\footnotetext{
${ }^{3}$ Providing children privileges such as cell phones, driving them to provide time with friends, buying video games, etc. are costly for parents in terms of time and money, and for simplicity $w$ is effectively transferred one for one from parents to children. The latter is unnecessary however; it would be sufficient if parents receive disutility from granting privileges when their child has shown no effort in school.
} 
reporting. Inaccurate priors and high monitoring costs may also be an issue as well. Focusing on Perfect Bayesian Nash Equilibria with parameters such that high types always exert effort in school but low types may not, the following comparative statics hold. Proofs and conditions are in the appendix.

Proposition 1. There is a positive association between child disclosure and effort in school and a negative association between parental monitoring and student performance. Further, poor school-parent reporting is associated with worse performance.

The intuition is straightforward: high types will work and voluntarily disclose information. Parents, observing the verifiable reports, have no need to monitor their children. Parents will only monitor if there is no child disclosure and low types are less likely to disclose. This generates the positive correlation between child disclosure and parental monitoring. Poor school-parent reporting implies greater uncertainty regarding whether or not a report exists. This poor reporting makes parents less certain that their child is of low type, which allows kids to shirk more than otherwise.

Proposition 2. Upwardly-biased beliefs and higher monitoring costs imply children will exert less effort in school, ceteris paribus. Reducing this bias or monitoring costs increases effort.

Providing parents frequent information about their child's academic progress lowers the cost of monitoring $m$, which implies a theoretical increase in child effort, but information could have further impact by adjusting parental beliefs about their child's type. The latter could lead to longer-run treatment effects. In addition to contemporaneous effects on academic outcomes, the empirical section examines the impact on parental beliefs and longer-run outcomes as well.

To understand whether parents overstate their child's effort, I analyze a survey item asking parents to estimate the number of assignments their child has missed in math class. I then compare this estimate with the true number of missing assignments. Figure 4 shows the density of true number of math assignments missed by a student minus the number of missed 
assignments estimated by parents. Parents underestimate the number of missed assignments by 8 assignments, on average $4^{4}$ This is consistent with other studies that examine parental beliefs about their child's effort in school. In Los Angeles public schools, a study on school absenteeism and asthma (Bonilla et al.,2005) finds that parents overestimate their child's school attendance. These results are also consistent with other education contexts in which parents have incorrect beliefs, such as parents' perception of the technology of skill formation (Cunha et al., 2013).

Similar to the findings by Kerr and Stattin (2000) and Stattin and Kerr (2000), actions associated with parental monitoring and a lack of disclosure are negatively associated with achievement in the context of this study. Using data from a survey of parents, Table 1 shows that contacting the school about their child's academic performance, taking away privileges from their child, and responding that their child does not tell them enough about their school work or grades are all negatively associated with GPA (Columns (2)-(4)). Further, overstating their child's effort in math class is negatively associated with GPA as well (Column (1)).

\section{Background and Experimental Design}

\section{A Background}

The experiment took place at a K-12 school during the 2010-2011 school year. This school is part of Los Angeles Unified School District (LAUSD), which is the second largest district in the United States. The district has graduation rates similar to other large urban areas and is low performing according to its own proficiency standards: $55 \%$ of LAUSD students graduate high school within four years, $25 \%$ of students graduate with the minimum requirements to attend California's public colleges, 37\% of students are proficient in English-Language Arts and $17 \%$ are proficient in math

\footnotetext{
${ }^{4}$ The median and mean are similar.

${ }^{5}$ This information and school-level report cards can be found online at http://getreportcard.lausd.net/reportcards/reports.jsp.
} 
The school is in a low-income area with a high percentage of minority students. $90 \%$ of students receive free or reduced-price lunch, $74 \%$ are Hispanic and $21 \%$ are Asian. Compared to the average district scores above, the school performs less well on math and English state exams; $8 \%$ and $27 \%$ scored proficient or better in math and English respectively. $68 \%$ of teachers at the school are highly qualified, which is defined as being fully accredited and demonstrating subject-area competence ${ }^{6}$ In LAUSD, the average high school is $73 \%$ Hispanic, $4 \%$ Asian and $89 \%$ of teachers are highly qualified. $]^{7}$

The school context has several features that are distinct from a typical LAUSD school. The school is located in a large building complex designed to house six schools and to serve 4,000 students living within a nine block radius. These schools are all new, and grades K-5 opened in 2009. The following year, grades six through eleven opened. Thus in the 2010-2011 school year the sixth graders had attended the school in the previous year while students in grades seven and above spent their previous year at different schools. Families living within the nine-block radius were designated to attend one of the six new schools but were allowed to rank their preferences for each. These schools are all pilot schools, which implies they have greater autonomy over their budget allocation, staffing, and curriculum than the typical district school. $8^{8}$

\section{B Experimental Design}

The sample frame consisted of all 462 students in grades six through eleven enrolled at the school in December of 2010. Of those, 242 students' families were randomly selected to receive the additional information treatment. This sample was stratified along indicators for being in high school, having had a least one D or F on their mid-semester grades, having a

\footnotetext{
${ }^{6}$ Several papers have shown that observable teacher characteristics are uncorrelated with a teacher's effect on test scores (Aaronson et al., 2008; Jacob and Lefgren, 2008; Rivken et al., 2005). Buddin (2010) shows this result applies to LAUSD as well.

${ }^{7}$ This information is drawn from the district-level report card mentioned in the footnote above.

${ }^{8}$ The smaller pilot school system in Los Angeles is similar to the system in Boston. Abdulkadiroglu et al. (2011) find that the effects of pilot schools on standardized test scores in Boston are generally small and not significantly different from traditional Boston public schools. For more information on LAUSD pilot schools, see http://publicschoolchoice.lausd.net/sites/default/files/Los\%20Angeles\%20Pilot\%20Schools\%20Agreement\%20\%28Signed\%29.pdf.
} 
teacher think the service would helpful for that student, and having a valid phone number $\square^{9}$ Students were not informed of their family's treatment status nor were they told that the treatment was being introduced. Teachers knew about the experiment but were not told which families received the additional information. Interviews with students suggest that several students discussed the messages with each other.

The focus of the information treatment was missing assignments, which included homework, classwork, projects, essays and missing exams. Each message contained the assignment name or exam date and the class it was for whenever possible. For some classes, this name included page and problem numbers; for other classes it was the title of a project, worksheet or science lab. Overwhelmingly, the information provided to parents was negative - nearly all about work students did not do. The treatment rule was such that a single missing assignment in one class was sufficient to warrant a message home. All but one teacher accepted late work for at least partial credit. Parents also received current-grades information three times and a notification about upcoming final exams.

The information provided to parents came from teacher grade books gathered weekly from teachers. 14 teachers in the middle school and high school were asked to participate by sharing their grade books so that this information could be messaged to parents. The goal was to provide additional information to parents twice a month if students missed work. The primary constraint on provision was the frequency at which grade books were updated. Updated information about assignments could be gathered every two-to-four weeks from nine of the fourteen teachers. Therefore these nine teachers' courses were the source of information for the messages and the remaining teachers' courses could not be included in the treatment. These nine teachers were sufficient to have grade-book level information on every student.

The control group received the default amount of information the school provided. This included grade-related information from the school and from teachers. Following LAUSD

\footnotetext{
${ }^{9}$ The validity of the phone number was determined by the school's automated-caller records.
} 
policy, the school mailed home four report cards per semester. One of these reports was optional - teachers did not have to submit grades for the first report card of the semester. The report cards contained grades, a teacher's comment for each class, and each teacher's marks for cooperation and work habits. All school documents were translated into Spanish and Korean, and the school employed several Korean and Spanish translators. Parent-teacher conferences were held once per semester. Attendance for these conferences was very low for the high school (roughly 15\% participation) but higher for the 7th and 8th grade (roughly $50 \%)$ and higher still for the 6 th grade (100\%). Teachers could also provide information to parents directly. At baseline, most teachers had not contacted any parents. No teacher had posted grades on the Internet though two teachers had posted assignments.

Figure 1 shows the timeline of the experiment and data collection. Baseline data was collected in December of 2010. That same month, contact numbers were culled from emergency cards, administrative data and the phone records of the school's automated-calling system. In January 2011, parents in the treatment group were called to inform them that the school was piloting an information service provided by a volunteer from the school for half the parents at the school. Parents were asked if they would like to participate, and all parents consented, which implies no initial selection into treatment. These conversations included questions about language preference, preferred method of contact-phone call, text message or email - and parents' understanding of the A-F grading system. Most parents requested text messages $(79 \%)$, followed by emails $(13 \%)$ and phone calls $(8 \%){ }^{10}$

The four mandatory grading periods after the treatment began are also shown, which includes first-semester grades. Before the last progress report in May, students took the California Standards Test (CST), which is a state-mandated test that all students are supposed to take.11 Surveys of parents and students were conducted over the summer in July and August. Lastly, course grades from February 2012, more than one year after the experiment began and seven months after its conclusion, were also collected the following school year.

\footnotetext{
${ }^{10} \mathrm{~A}$ voicemail message containing the assignment-related information was left if no one picked up the phone.

${ }^{11}$ Students with special needs can be exempted from this exam.
} 
Notifications began in early January of 2011 and were sent to parents of middle school students and high school students on alternating weeks. This continued until the end of June, 2011. A bar graph above the timeline charts the frequency of contact with families over six months. The first gap in messages in mid February reflects the start of the new semester and another gap occurs in early April during spring vacation. This graph shows there was a high frequency of contact with families.

\section{Contamination}

The most severe, documented form of contamination occurred when middle school teachers had a school employee replicate the treatment for all students, treatment and control. This employee called parents regarding missing assignments and set up parent-teacher conferences in addition to the school-wide conferences. This contamination began four-to-five weeks after the treatment started and makes interpreting the results for the middle school sample difficult.

For the high-school sample, a math teacher threatened his classes (treatment and control students) with a notification via the information treatment if they did not do their assignments. These sources of contamination likely bias the results toward zero.

Due to the degree of contamination in the middle school, I analyze the results for the stratified subgroups of middle school and high school students separately.

\section{Data and Empirical Strategy}

\section{A Baseline Data}

Baseline data include administrative records on student grades, courses, attendance, race, free-lunch status, English-language skills, language spoken at home, parents' education levels and contact information. There are two measures of GPA at baseline. For $82 \%$ of high school students, their cumulative GPA prior to entering the school is also available, but 
this variable is missing for the majority of middle school students. The second measure of GPA is calculated from their mid-semester report card, which was two months before the treatment began. At the time of randomization only mid-semester GPA was available. Report cards contain class-level grades and teacher-reported marks on students' work habits and cooperation. As stated above, there is an optional second-semester report card, however the data in this paper uses mandatory report cards to avoid issues of selective reporting of grades by teachers. Lastly, high school students were surveyed by the school during the first semester and were asked about whom they lived with and whether they have Internet access. $73 \%$ of students responded to the school's survey.

Teachers were surveyed about their contact with parents and which students they thought the information treatment would be helpful for. The latter is coded into an indicator for at least one teacher saying the treatment would be helpful for that student.

\section{B Achievement-Related Outcomes}

Achievement-related outcomes are students' grades, standardized test scores and final exam or project scores from courses. Course grades and GPA are drawn from administrative data on report cards. There are four mandatory report cards available after the treatment began, but only end-of-semester GPA and grades remain on a student's transcript. There are two sets of end-of-semester grades: transcript grades obtained during the school year in which the experiment was conducted and transcript grades obtained seven months after the experiment concluded. Final exam and project grades come from teacher grade books and are standardized by class.

The standardized test scores are scores from the California Standards Tests. These tests are high-stakes exams for schools but are low stakes for students. The math exam is subdivided by topic: geometry, algebra I, algebra II and a separate comprehensive exam for students who have completed these courses. The English test is different for each grade. Test scores are standardized to be mean zero and standard deviation one for each different 
test within the sample.

\section{Effort-Related Measures}

Measures of student effort are student work habits, cooperation, attendance and assignment completion. Work habits and cooperation have three ordered outcomes: excellent, satisfactory and unsatisfactory. There is a mark for cooperation and work habits for each class and each grading period, and students typically take seven to eight classes per semester. Assignment completion is coded from the teacher grade books. Missing assignments are coded into indicators for missing or not.

There are three attendance outcomes. Full-day attendance rate is how often a child attended the majority of the school day. Days absent is a class-level measure showing how many days a child missed a particular class. The class attendance rate measure divides this number by the total days enrolled in a class.

\section{Parental Investments and Family Responses to Information}

Telephone surveys were conducted to examine parent and student responses to the intervention not captured by administrative data. For parents, the survey asked about their communication with the school, how they motivated their child to get good grades, and their perceptions of information problems with their child about schoolwork. Parent-teacher conference attendance was obtained from the school's parent sign-in sheets. The student survey asked about their time use after school, their communication with their parents and their valuations of schooling, 12

The parent and student surveys were conducted after the experiment ended by telephone. $52 \%$ of middle-school students' families and $61 \%$ of high-school students' families responded to the telephone survey: ${ }^{13}$ These response rates are analyzed in further detail below.

\footnotetext{
${ }^{12}$ Students were also asked to gauge how important graduating college and high school is to their parents, but there was very little variation in the responses across students so these questions are omitted from the analysis.

${ }^{13}$ The school issued a paper-based survey to parents at the start of the year and the response rate was under $15 \%$. An employee of LAUSD stated that the response rates for their paper-based surveys is $30 \%$.
} 
To reduce potential social-desirability bias - respondents' desire to answer questions as they believe surveyors would prefer - the person who sent messages regarding missing assignments and grades did not conduct any surveys. No explicit mention about the information service was made until the very end of the survey.

\section{E Attrition, Non Response, Missing CST Scores}

Of the original of 462 students in the sample, 32 students left the school, $8 \%$ of whom were in the treatment group and $6 \%$ of whom were in the control group ${ }^{14}$ The most frequent cause of attrition is transferring to a different school or moving away. Students who left the school are lower performing than the average student. The former have significantly lower baseline GPA and attendance as well as poorer work habits and cooperation. Table A.1 shows these correlates in further detail for middle school and high school students separately. Attrition is more substantial for the longer-run followup, seven months after the conclusion of the intervention: $14 \%$ of students leave the sample between the end of the school year (June, 2011) to the end of the semester followup (February, 2012). This is not correlated with treatment status, however (Table A.2).

Just over one third of high-school parents did not respond to the survey 15 Table A.3 shows nonresponse for families of high school students. Nonresponse is uncorrelated with treatment status for both children and parents. However, if those who did not respond differ from the typical family, then results based on the surveys may not be representative of the school population. This is true, as a regression of an indicator for non response on baseline characteristics shows the latter are jointly significant (results not shown). Nonetheless, the majority of families responded and provide insight into how they responded to the additional information.

Lastly, many students did not take the California Standards Test. $8 \%$ of scores are missing

\footnotetext{
${ }^{14}$ This degree of attrition is not unusual in this area. Another study at a Los Angeles area school documented $7 \%$ attrition from the start to the end of the school year, and substantially more attrition from spring to fall (Dudovitz et al., 2013).

${ }^{15}$ For comparison, LAUSD has said their non-response rate for parent surveys is roughly double this number.
} 
for math and $7 \%$ of scores are missing for English. These tests were taken on different days. Table A.4 in the appendix shows the correlates of missing scores for high school students. Baseline controls are added for each of the first three columns with an indicator for missing math scores as the dependent variable. The remaining three columns perform the same exercise for missing English scores. The treatment is negatively and significantly associated with missing scores. The potential bias caused by these missing scores is analyzed in the results section on test scores.

\section{F Descriptive Statistics}

In practice, the median treatment-group family was contacted 10 times over six months. Mostly mothers were contacted (62\%), followed by fathers $(24 \%)$ and other guardians or family members (14\%). 60\% of parents asked to be contacted in Spanish, 32\% said English was acceptable, and $8 \%$ wanted Korean translation.

Figures 2 and 3 depict GPA and teacher-marked behavior distributions from the mandatory report card at baseline for all students.16 For every report card, work habits and cooperation are graded as excellent, satisfactory or unsatisfactory for each student's class. Teachers describe the work habits grade as measuring how on task a student is while cooperation reflects the respectfulness of their classroom behavior. Figure 3 shows the majority of students receive satisfactory or excellent marks for class cooperation and only $10 \%$ of students receive an unsatisfactory mark. Work-habit grades are more uniformly distributed across the three possible marks.

Table 2 presents baseline-summary statistics across the treatment group and the control group for high school students. Panel A contains these statistics for the original sample while Panel B excludes attriters to show the balance of the sample used for estimations. Measures of works habits and cooperation are coded into indicators for unsatisfactory or not and excellent or not. Of the 13 measures, one difference - the fraction of female students - is

\footnotetext{
${ }^{16}$ For high school students, $22 \%$ of students have a baseline GPA of 1.00 or below, while $19 \%$ of students have 3.00 or above.
} 
significantly different (p-value of .078) between the treatment and control group in Panel A. All results are robust to adding gender as a control. Work habits and students' cumulative GPA from their prior grades are better (but not significantly) for the control group than the treatment group. Panel B shows that baseline GPA is .06 points higher for the control group than the treatment group in the sample used for analysis, and as shown below, results are sensitive to this control. One concern with this baseline difference is mean reversion, however students' prior GPA, which is a cumulative measure of their GPA over several years, also shows the treatment group is lower achieving than the control group. In addition, GPA for the control group is highly persistent from the end of the first semester to the end of the second semester. A regression of the latter on the former yields a coefficient near one. 17

\section{G Empirical Strategy}

The empirical analyses estimate intent-to-treat effects. Families in the treatment group may have received fewer or no notifications because their child has special needs (13 families); the guidance counselor requested them removed from the list due to family instability (two families); or the family speaks a language other than Spanish, English or Korean (two families). All of these families are included in the treatment group.

To measure the effect of additional information on various outcomes, I estimate the following

$$
y_{i}=\alpha+\beta * \text { Treatment }_{i}+X_{i}^{\prime} \gamma+\varepsilon_{i}
$$

Control variables in $X$ include baseline GPA and cumulative GPA from each student's prior school, grade indicators and strata indicators. The results are robust to various specifications so long as a baseline measure of GPA is controlled for, which most likely makes a difference due to the .06 point difference at baseline.

\footnotetext{
${ }^{17}$ Mean reversion does occur between students' prior GPA and their baseline GPA, however this reversion does not differ by treatment status (results available on request).
} 
I estimate equation 11 with GPA as a dependent variable. To discern whether there were any differential effects by subject or for "targeted" classes - those classes for which a teacher shared a grade book in a timely fashion-I also use class grades as a dependent variable. ${ }^{18}$ This regression uses the same controls as 1 above but the standard errors are clustered at the student level. ${ }^{19}$ End-of-semester grades are coded on a four-point scale to match GPA calculations 20

Similar to class grades, there is a work habit mark and a cooperation mark for each student's class as well. I estimate the effect of additional information on these marks using an ordered-Probit model that pools together observations across grading periods and clusters standard errors at the student level. The controls are the same as above with additional grading-period fixed effects. I report marginal effects at the means, but the average of the marginal effects yields similar results.

Effects on full-day attendance and attendance at the classroom level use the same specification and controls as the specifications for GPA and class grades, respectively.

\section{Results}

\section{The Effect of the Treatment on School-to-Parent Contact}

Table 3 assesses the effect of the treatment on survey measures of school-to-parent contact. Parents were asked how often the school contacted them during the last month of school regarding their child's grades or schoolwork. During this time all parents had been sent a progress report about their child's grades. The first column shows how much more often the treatment group in high school was contacted by the school than the control group, controlling for baseline GPA and cumulative GPA from students' prior schools ${ }^{21}$ The treatment

\footnotetext{
${ }^{18}$ Recall that only nine of the 14 teachers updated their grade books often enough so that assignment-related information could be provided to parents. The class-grades regression estimates whether treated students in those nine teachers' classes showed greater gains than the classes of teachers who did not update grades often enough to participate.

${ }^{19}$ Clustering at the teacher level or two-way clustering by teacher and student yield marginally smaller standard errors.

${ }^{20} \mathrm{~A}$ is coded as $4, \mathrm{~B}$ as $3, \mathrm{C}$ as $2, \mathrm{D}$ as 1 and $\mathrm{F}$ as 0 .

${ }^{21}$ The results without controls are extremely similar.
} 
increased contact from the school regarding their child's grades and schoolwork by $187 \%$ relative to the control group. The dependent variable in the second column measures the fraction of people that were contacted by the school more than once. This fraction increases by $158 \%$ relative to the control group. The treatment had large effects on both the extensive margin of contact and the intensive margin of contact from the school regarding student grades.

Recall that the experiment was contaminated when the middle school teachers had an employee call their students regarding missing assignments. Mechanically, there should be a positive effect for middle school families since parents did receive messages via the treatment. The employee who contacted families regarding missing work did so for all studentstreatment and control-likely resulting in parents being contacted more than once regarding the same missing assignment. While there is no measure of how often parents were contacted with new information, if the contamination were significant, we would expect school-contact effects to be smaller for the middle school sample. The results are considerably weaker for the middle school students. Contact increased by $106 \%$ and the fraction contacted increased by $69 \%$.

\section{Effects on Achievement Measures}

\section{A GPA}

Figure 5 tracks average GPA in the treatment and control groups over time. The red vertical line indicates when the treatment began, which is about one month before the first semester ended in mid February. There is a steady decrease in GPA for the control group after the first semester ends in February followed by a spike upward during the final grading period. The treatment group does not experience this decline and still improves in the final grading period. Teachers reported that students work less in the beginning and middle of the semester and "cram" during the last grading period to bring up their GPA, which may 
negatively affect learning (Donovan, Figlio and Rush, 2006).

The regressions in Table 4 reinforce the conclusions drawn from the graphs described above. Column (1) shows the effect on GPA with no controls. The increase is .15 and is not significant, however the treatment group had a .06 point lower GPA at baseline. Adding a control for baseline GPA raises the effect to .20 points and is significant at the $5 \%$ level (column (2)). The standard errors decrease by 35\%. The third column adds controls for GPA from students' prior schools and grade level indicators. The treatment effect increases slightly to .23 points. The latter converts to a .19 standard deviation increase in GPA over the control group. The results in Table 5 are estimates of the treatment effect on class grades. Column (1) shows this effect is nearly identical to the effect on final GPA. ${ }^{22}$ Column (2) shows the effect on targeted classes - those classes for which a teacher was asked to participate and that teacher provided a grade book so that messages could be sent home regarding missing work. This analysis is underpowered, but the interaction term is positive and not significant (p-value equals .16). Columns (3) and (4) show that math classes had greater gains than English classes (p-values equal .11 and .85, respectively). This effect disparity coincides with the difference in effects shown later for standardized tests scores.

The last column shows the effects for students in which at least one teacher thought additional information would be especially helpful for them. The treatment effect is negative but not significant ( $\mathrm{p}$-value equals .24). Most likely there was no differential effect for these students, and if anything the effect appears negative. Teachers appear to have no additional information about whom the treatment would be most helpful for. While teachers generally take in new students every year, the teachers in this sample had known students for three months at the time this variable was measured at baseline.

Even though grading standards are school specific, the impact on GPA is important. In the short run, course grades in required classes determine high school graduation and higher education eligibility. In the longer run, several studies find that high school GPA is

\footnotetext{
${ }^{22}$ The similarity in effects between this unweighted regression on individual grades and the regression on GPA is because there is small variation in the number of classes students take.
} 
the best predictor of college performance and attainment (for instance Geiser and Santelices, 2007). GPA is also significantly correlated with earnings even after controlling for test scores (Rosenbaum, 1998; French et al., 2010). 23

\section{B Final Exams, Projects and Standardized Test scores}

Additional information causes exam and final project scores to improve by .16 standard deviations (significant at the 5\% level, Table 6). However, teachers enter missing finals as zeros into the grade book. On average, $18 \%$ percent of final exams and projects were not submitted by the control group. The effect on the fraction of students turning in their final exam or project is large and significant. Additional information reduces this fraction missing by $42 \%$, or 7.5 percentage points.

Ideally, state-mandated tests are administered to all students, which would help separate out the treatment effect on participation from the effect on their score. Unfortunately, many students did not take these tests, and as shown above, missing a score is correlated with treatment status and treatment-control imbalance - prior test scores of treatment-group students are .26 lower and baseline GPA .13 points lower (results not shown). To see whether those who did not take the test responded to the treatment differently than those who did take the test, I compare the GPA results of those who took the standardized tests with those who did not. Specifically, the indicator for treatment is interacted with an indicator for having a math test score or English test score as follows.

$$
\text { GPA }_{i}=\beta_{0}+\beta_{1} * \text { Treatment }_{i}+\beta_{2} * \text { Treatment }_{i} * 1\left(\text { HasScore }_{i}\right)+X_{i}^{\prime} \gamma+\varepsilon_{i}
$$

Where the variable HasScore ${ }_{i}$ is an indicator for either having an English test score or having a math test score. The coefficient on the interaction term, $\beta_{2}$, indicates whether those who have a test score experienced different effects on GPA than those who do not have

\footnotetext{
${ }^{23}$ One caveat, however, is that the mechanisms that generate these correlations may differ from the mechanisms underlying the impact of additional information on GPA.
} 
a test score. This achievement effect might correlate with the achievement effect on test scores. If $\beta_{2}$ is large, it suggests how the test-score results might be biased-upwards if $\beta_{2}$ is positive and downwards is $\beta_{2}$ is negative.

Table A.5 shows the results of this analysis. The coefficients on the interaction term for having a score is insignificant (p-value equals .14) but is large and negative. Thus there is some evidence that the treatment effect is smaller for those with test scores compared to those without, which may bias the estimates on test scores downward.

To account for this potential bias, the effects on math and English test scores are shown with a varying number of controls. The first and fourth columns in Table 7 control only for baseline GPA. The effect on math and English scores are .08 and -.04 standard deviations respectively. Columns (2) and (5) add controls for prior test scores, demographic characteristics and test subject. The treatment effect on math scores is .21 standard deviations, but remains near zero for English scores. Finally, if the treatment induces lower performing students to take the test, then those with higher baseline GPA might be less affected by this selection. This means we might see a positive coefficient on the interaction term between baseline GPA and the treatment. Columns (3) and (6) add this interaction term. While the interaction term is small for English scores, for math scores it implies that someone with the average GPA of 2.01 has a .20 standard deviations higher math score due to the additional information provided to their parents.24

This disparity between math and English gains is not uncommon. Bettinger (2010) finds financial incentives increase math scores but not English scores and discusses several previous studies (Reardon, Cheadle, and Robinson, 2008; Rouse, 1998) on educational interventions that exhibit this difference as well. There are three apparent reasons the information intervention may have had a stronger effect on math than English. First, the math teachers in this sample provided more frequent information on assignments that allowed more messages to be sent to parents. Potentially, this frequency might mean students fall less behind.$^{25}$

\footnotetext{
${ }^{24}$ This marginal effect at the mean is significant at the $5 \%$ level.

${ }^{25}$ This theory is difficult to test since there is no within-class variation in grade-book upkeep or message frequency conditional
} 
Second, $30 \%$ of students are classified as "limited-English proficient," which means they are English-language learners and need to pass a proficiency test three years in a row to be reclassified. Looking at class grades, these students tend to actually perform better in English classes, though interacting the treatment with indicators for language proficiency and English classes yields a large and negative coefficient (results not shown). In contrast, this coefficient is negative but $75 \%$ smaller when the interaction term includes an indicator for math classes rather than English classes. This means that the treatment effect for students with limited English skills is associated with smaller gains for English than math, which may in part drive the disparity in effects. Lastly, math assignments might provide better preparation for the standardized tests compared to English assignments if they more closely approximate the problems on the test.

\section{Mechanisms}

The goal of this is section is to understand how parents responded to the additional information in the context of the theoretical framework and what effect this had on student behaviors.

\section{Impact of Information on Parental Beliefs}

To study the impact of the additional information on parents' beliefs about their child's effort, I discretize parents' belief about their child's missing assignments into the four categories in Table 8 and I estimate a multinomial-Logit model. Panel A shows the treatment causes parents to revise their beliefs. The marginal effects show a large, statistically significant reduction in the probability of responding "I don't know" response and a large, statistically significant increase in the probability responding their child has missed 3-5 assignments. There are no changes in the other categories. Second, the treatment impacts the size of the on missing an assignment. 
bias. Panel B shows results from a linear model for effects on the continuous "Difference from Truth" variable. The treatment significantly reduces the magnitude of the bias. This revision is particularly stark for parents of students with low baseline GPA, as indicated in the second column of Table 8, Causal mediation analysis (Heckman and Pinto, 2013; Imai et al., 2010; Valeri and VanderWeele, 2013) shows that this belief revision explains approximately $30 \%$ of the treatment effect (results available upon request).

This result is corroborated by results in Panel C, which shows that parents lacked awareness of the information problems with their child regarding school work. Column (1) reports the answers to the question, "Does your child not tell you enough about his or her school work or grades?" Parents in the treatment group are almost twice as likely to say yes as parents in the control group.

\section{A How Parents Used the Additional Information}

A change in parental beliefs and a reduction in monitoring costs should cause to parents to increase the use of monitoring and incentives. Panel A of Table 9 reflects impacts on measures of parental monitoring. Over the last semester, parents in the treatment group were $85 \%$ more likely to contact the school regarding their child's schoolwork or grades, and this is corroborated by the school's data on parent-teacher conference attendance, which increased by $53 \%$. There is little impact on the number of times parents ask their children about their schoolwork. The last column shows the coefficient on the treatment is negative and insignificant.

Panel B of Table 9 shows how parents interacted with their children. In terms of incentives, parents were asked how many privileges they took away from their child in the last month of school, which increased by nearly $100 \%$ for the treatment group (Column (1)). The most common privilege revoked by parents involved electronic devices - cell phones, television, Internet use and video games - followed by seeing friends 26 There is evidence parents also

\footnotetext{
${ }^{26} \mathrm{An}$ open-ended question also asked students how their parents respond when they receive good grades. $41 \%$ said their
} 
spoke about college more often to their child, perhaps emphasizing the future returns to schooling in addition to the threat of punishment. Parents provide little direct assistance to their children overall. Children were asked how often they received help with their homework from their parents on a three point scale ("never," "sometimes," or "always," coded from zero to two). Overwhelmingly parents never help their children directly, (80\%) and the treatment has no significant effect on this behavior. Finally, the last column reports answers to whether parents agree they can help their child do their best at school. Parents in the treatment group are 16 percentage points more likely to say yes.

\section{B Student Inputs and Valuations of Schooling}

The effects on work habits and cooperation are consistent with the effects on GPA. Figure 6 shows that the treatment group exhibits less unsatisfactory work habits than control group, on average. Figure 7 shows that excellent work habits increase steadily for the treatment group over time. Excellent cooperation, shown in Figure9, dips in the middle of the semester but rises at the end. The average levels of uncooperative behavior exhibit a similar pattern to unsatisfactory work habits (Figure 8).

Table 10 provides the ordered-Probit estimates for work habits and cooperation (Panel A). Additional information reduces the probability of unsatisfactory work habits by $24 \%$, or a six-percentage point reduction from the overall probability at the mean. This result mirrors the effect on excellent work habits for high school students, which increases by sevenpercentage points at the mean. The probability of unsatisfactory cooperation is reduced by $25 \%$ and the probability of excellent cooperation improves by $13 \%$.

Panel B shows OLS estimates of the effects on attendance. The effect on full-day attendance is positive though not significant, however full-day attendance rates are already above 90\% and students are more likely to skip a class than a full day. Analysis at the class level shows positive and significant effects. The treatment reduces classes missed by $28 \%$. The parents take them out or buy them something, 50\% said their parents are happy, proud or congratulate them, and $9 \%$ said their parents do not do anything. 
final column of Panel B contains the estimated probability of missing an assignment. The average student does not turn in $20 \%$ of assignments. Assignments include all work, classwork and homework, and the grade books do not provide enough detail to discern one from the other ${ }^{27}$ At the mean, the treatment decreases the probability of missing an assignment by $25 \%$.

The first three columns of Table 10 (Panel A) show how students' work habits changed outside of school. Tutoring attendance over the semester increased $42 \%$. The coefficient is marginally insignificant at standard levels (p-value equals .11). Tutoring was offered by teachers after school for free. The positive effect on tutoring is at least partially due to several teachers' requirement that missing work be made up during their after school tutoring to prevent cheating. The second column shows the effect on whether students did their homework at the last minute, which was coded from zero to two for "never," "sometimes" or "always." Students in the treatment group were significantly less likely to do their homework at the last minute. Nonetheless, student study hours at home did not significantly increase, which implies that most of the gains in achievement are due to improved work habits at school.

The remaining two columns of Panel A show students' valuations of schooling on a fourpoint scale. Students in the treatment group are more likely to say grades are important, but no more likely to say that college is important. One interpretation of these results is that grades are important because students will be punished if they do not do well, but their intrinsic valuation of schooling has not changed.

These behavioral effects show that increased student productivity during school hours is an important mechanism underlying the effects of additional information. Assignments may be started in class but might have to be completed at home if they are not finished during class (e.g. a lab report for biology or chemistry, or worksheets and writing assignments in history and English classes). If students do not complete this work in class due to poor attendance

\footnotetext{
${ }^{27}$ Several teachers said that classwork is much more likely to be completed than work assigned to be done at home.
} 
or a slow work pace, they may not do it at home. The information treatment discourages poor attendance and low in-class productivity, which in turn may increase learning. The following section discusses what parent behaviors could have caused this result.

\section{Longer-Run Effects and Ruling out Alternative Explanations}

The fact that the randomization was at the student level, within classrooms, raises two potential concerns. The first concern is teachers could have artificially raised treatmentgroup student grades to reduce any hassle from parental contact. If this were the case, the grade improvements observed in the treatment group would not be due to the effect of additional information on student effort and would not correspond to any actual improvement in student performance. A second concern is that teachers paid more attention to treatmentgroup students at the expense of attention for control-group students. This reallocation of attention to treatment-group students could reduce achievement for control students and bias effects away from zero. While these are potential issues, several results undermine support for these interpretations.

The most definitive results contradicting these interpretations are the significant effects on measures of student effort and parental investments that are less likely to be manipulated by teachers. The treatment group has higher attendance rates, higher levels of student-reported effort such as tutoring attendance and timely work completion, and a greater fraction of completed assignments. These results suggest that students indeed exerted more effort as a result of the information treatment. Consistent with this interpretation, the survey evidence from parents suggests that treatment-group parents took steps to motivate their children in response to the additional information beyond those of control-group parents, such as more intensive use of incentives.

It is also plausible that teachers who did not participate in the information intervention were less aware of who is in the treatment group versus the control group and therefore less likely to change their behavior as a result of the experiment. Consistent with the results 
above, the class-level analysis shows that students' grades also improved in the classes of these non-participating teachers (Table 5, column two).

Third, an analysis of treatment effects on control group students provides some evidence on whether the control group's grades increased or decreased as a result of the treatment. Though the experiment was not designed to examine peer effects, random assignment at the student level generates classroom-level variation in the fraction of students treated. Table A.6 shows the results from a regression of control students' class grades on the fraction of students treated in each respective class. While not statistically significant (p-value equals .27), the point estimate implies a positive impact of the fraction of students treated in a given classroom on the control students (a 25 percentage point increase in the fraction of students treated in a given classroom causes control group students' grades to increase by .14 points). This suggests that the gains observed among treatment students did not come at the expense of control students. To the contrary, there may have been positive spillovers onto control-group students' achievement that bias the effects of additional information toward zero.

Lastly, I present impacts on grades seven months after the conclusion of the treatment. A reminder or recency effect is less likely to be present at this stage, and a change in parental beliefs could lead to longer-run effects on outcomes. Despite balanced attrition from the school over summer months and the following semester (see Table A.2 for an analysis), Table 12 shows effects substantially persist. Column (1) shows the GPA effect is .15 and effect on grades is .17, which are $66 \%$ and $75 \%$ as large as the original treatment effects, respectively.

\section{Middle School Results}

Table 13 summarizes the effects on achievement and effort-related outcomes for middle school students, which are mostly small and not significantly different from zero. These results are 
consistent with the effects on how parents used the additional information, how children responded, and parents' awareness and demand for information (Table 14). Based on these results and the contamination, it is difficult to discern what effect the treatment would have had on younger students.

There are several reasons the additional information may have had less effect on younger children. First, the middle school students have less margin to improve: Their GPA is almost a full standard deviation higher than high school students' GPA, middle school students miss $7.5 \%$ of their assignments compared to high school students who miss $20 \%$ of their assignments, and attendance and behavior are also better for middle school students. However if this were the only cause for small effects, there could still be an impact on students who were lower-performing at baseline. Unfortunately the study is underpowered to examine subgroups in the middle school, but point estimates show students with higher GPA respond more positively to additional information (results not shown).

A second reason there might be smaller effects for middle school students is that parents might be able to control younger children better than older children. It might be less costly for parents to motivate their children or information problems arise less frequently. There is some support for this hypothesis since teacher-measured behavior at baseline is better for middle school students than high school students, which might correlate with parents' ability to control their child. Third, the repeated messages to middle school parents through the information treatment and the contamination by the school employee may have annoyed them. If they had already resolved an issue such as a missing assignment, receiving a second message regarding that work might have been confusing and frustrating. Parents could have viewed the information treatment as less reliable given the lack of coordination about schoolto-parent contact and started ignoring it, which might explain the small negative coefficients on several middle school outcomes.

Lastly, parents of middle-school students might already obtain information about their child's education more actively, which is reflected in the higher parent-teacher conference 
attendance. In addition, a comparison of the control groups in the high school and middle school shows that parents of middle school students are more likely to take away privileges from their children, be aware of information problems, contact the school about their child's grades, and feel that they can help their child try their best than parents of high school students in the control group ${ }^{28}$ It is possible that the contamination caused this higher level of involvement - meaning messages home did affect middle school parents - or it could be that these parents were already more involved than high school parents. If the latter, it leaves open the question of why this involvement wanes as children get older; perhaps parents perceive they have less control of their child's effort or that they no longer know how to help them. In short, the effect of additional information on younger children is inconclusive.

\section{Conclusion and Cost effectiveness}

This paper uses an experiment to answer how information asymmetries between parents and their children affect human capital investment and achievement. The results show these problems can be significant and their effect on achievement large. Additional information to parents about their child's missing assignments and grades helps parents motivate their children more effectively and changes parents' beliefs about their child's effort in school. Parents also become more aware that their child does not tell them enough about their academic progress. These mechanisms drive an almost .20 standard deviation improvement in math standardized test scores and GPA for high school students. There is no estimated effect on middle-school family outcomes, however there was severe contamination in the middle school sample. One positive aspect of this contamination is that it reflects teachers' valuation of the intervention, which has helped scale this work further.

However it is important to consider how well these results extrapolate to other contexts. While the student population is fairly representative of a large, urban school district like

\footnotetext{
${ }^{28}$ Results available upon request.
} 
Los Angeles Unified, there are several parameters of the education-production function that determine the effectiveness of increasing information to parents. Two salient factors are teacher and parent characteristics. Teacher quality affects both the capability of the school to provide information and the impact of student effort on achievement. If teachers do not frequently grade assignments, it is difficult to increase the amount of information to parents. If the quality of instruction is poor, increases in student effort may not convert into improvements in learning. For parents, the effects may differ by demographic characteristics as well. Information changes parental beliefs, which may be particularly relevant to first-generation families and those who lack strong educational backgrounds. Finally, the treatment lasted six months. The negative information about academic performance could create tension at home that might impact outcomes differently over the long run, which makes direct comparison to other, longer-run interventions difficult. However parents expressed a desire to continue the information service and treatment effects persisted into the following academic year, after the intervention concluded.

Importantly, this paper demonstrates a potentially cost-effective way to bolster student achievement: Provide parents frequent and detailed grade-book information. Contacting parents via text message, phone call or email took approximately three minutes per student. Gathering and maintaining contact numbers adds five minutes of time per child, on average. The time to generate a missing-work report can be almost instantaneous or take several minutes depending on the grade book used and the coordination across teachers ${ }^{29}$ For this experiment it was roughly five minutes. Teacher overtime pay varies across districts and teacher characteristics, but a reasonable estimate prices their time at $\$ 40$ per hour. If teachers were paid to coordinate and provide information, the total cost per child per .10 standard-deviation increase in GPA or math scores would be $\$ 156$. This cost-effectiveness analysis excludes the potentially significant time costs to parents and children.

Automating aspects of this process could reduce this costs further, especially because

\footnotetext{
${ }^{29}$ Some grade book programs can produce a missing assignment report for all of a student's classes.
} 
many districts pay fixed costs for data systems. In response to this experiment, the school and a learning management company collaborated to develop a feature that automatically text messages parents about their child's missing assignments directly from teachers' grade books, which has been scaled to a large district. Relative to other effective interventions targeting adolescent achievement, the additional marginal cost is quite low. 


\section{References}

[1] Aaronson, Daniel, Lisa Barrow and William Sander (2007). "Teachers and Student Achievement in the Chicago Public High Schools," Journal of Labor Economics, vol $25(1), 95-135$.

[2] Abdulkadiroğlu, Atila, Joshua D. Angrist, Susan M. Dynarski, Thomas J. Kane and Parag A. Pathak (2011). "Accountability and Flexibility in Public Schools: Evidence from Boston's Charters and Pilots," The Quarterly Journal of Economics, 126, 699-748.

[3] Akabayashi, Hideo (2005). "An Equilibrium Model of Child Maltreatment," Journal of Economic Dynamics \& Control 30(6): 993-1025.

[4] Andrabi, Tahir, Jishnu Das and Asim Ijaz Khwaja (2009). "Report Cards: The Impact of Providing School and Child Test-Scores on Educational Markets," Mimeo, Harvard University.

[5] Angrist, Joshua D., Susan M. Dynarski, Thomas J. Kane, Parag A. Pathak, Christopher R. Walters (2010). "Inputs and Impacts in Charter Schools: KIPP Lynn," American Economic Review: Papers and Proceedings, vol 100(2), 239-243.

[6] Angrist, Joshua D. and Victor Lavy (2002). "The Effects of High Stakes High School Achievement Awards: Evidence from a Randomized Trial," American Economic Review, vol 99(4), 1384-1414.

[7] Avvisati, Francesco, Marc Gurgand, Nina Guyon and Eric Maurin (2010). "The Influence of Parents and Peers on Pupils: A Randomized Experiment," Mimeo, Paris School of Economics.

[8] Berry, James (2011). "Child Control in Education Decisions: An Evaluation of Targeted Incentives to Learn in India," Mimeo, Cornell University. 
[9] Bettinger, Eric P. (2010). "Paying to Learn: The Effect of Financial Incentives on Elementary School Test Scores," NBER Working Paper No. 16333.

[10] Bettinger, Eric, Bridget T. Long, Philip Oreopoulos and Lisa Sanbonmatsu (2009). "The Role of Simplification and Information in College Decisions: Results from the H\&R Block FAFSA Experiment," NBER Working Paper No. 15361.

[11] Bettinger, Eric and Robert Slonim (2007). "Patience in Children: Evidence from Experimental Economics," Journal of Public Economics, vol 91(1-2): 343-363.

[12] Bonilla, Sheila, Sara Kehl, Kenny Kwong, Tricia Morphew, Rital Kachru and Craig Jones (2005). "School Absenteeism in Children With Asthma in a Los Angeles Inner City School," The Journal of Pediatrics 147(6): 802-806.

[13] Bridgeland, John M., John J. Dilulio, Ryan T. Streeter, and James R. Mason (2008). One Dream, Two Realities: Perspectives of Parents on America's High Schools, Civic Enterprises and Peter D. Hart Research Associates.

[14] Buddin, Richard (2010). "How Effective Are Los Angeles Elementary Teachers and Schools?" Retrieved online on April 2011, from http://s3.documentcloud.org/documents/19505/how-effective-are-los-angeleselementary-teachers-and-schools.pdf.

[15] Bursztyn, Leonardo and Lucas Coffman (2012). "The Schooling Decision: Family Preferences, Intergenerational Conflict, and Moral Hazard in the Brazilian Favelas," Journal of Political Economy, vol 120(3): 359-397.

[16] Cameron, Colin, Jonah Gelbach and Douglas Miller (2008). "Bootstrap-Based Improvements for Inference with Clustered Standard Errors," The Review of Economics and Statistics, vol 90(3): 414-427.

[17] Cosconati, Marco (2009). "Parenting Style and the Development of Human Capital in Children," Ph.D. dissertation, University of Pennsylvania. 
[18] Cunha, Flavio, Irma Elo and Jennifer Culhane (2013). "Eliciting Maternal Expectations about the Technology of Cognitive Skill Formation," NBER Working Paper No. 19144.

[19] Cunha, F., James J. Heckman, Lance Lochner and Dimitriy V. Masterov (2006), "Chapter 12 Interpreting the Evidence on Life Cycle Skill Formation," Handbook of the Economics of Education, vol 1: 697-812.

[20] Dobbie, Will and Roland G. Fryer (2011). "Are High Quality Schools Enough to Close the Achievement Gap? Evidence from the Harlem Children's Zone," American Journal: Applied Economics, vol 3(3), 158-187.

[21] Dudovitz, Rebecca, Ning Li and Paul Chung (2013). "Behavioral Self-Concept as Predictor of Teen Drinking Behaviors," Academic Pediatrics 13(4): 316-321.

[22] Dye, Ronald (1985). "Disclosure of Nonproprietary Information," Journal of Accounting Research 23(1): 123-145.

[23] French, Michael, Jenny Homer and Philip K. Robins (2010). "What You Do in High School Matters: The Effects of High School GPA on Educational Attainment and Labor Market Earnings in Adulthood." Mimeo, University of Miami, Department of Economics.

[24] Fryer, Roland G. (2010). "Financial Incentives and Student Achievement: Evidence from Randomized Trials," NBER Working Paper No. 15898.

[25] Fryer, Roland G. (2011). "Teacher Incentives and Student Achievement: Evidence from New York City Public Schools," NBER Working Paper No. 16850.

[26] Gelser, Saul and Marla V. Santelices (2007). "Validity of High-School Grades in Predicting Student Success Beyond the Freshman Year: High-School Record vs. Standardized Tests as Indicators of Four-Year College Outcomes," Research \& Occasional Paper Series: CSHE.6.07. 
[27] Grossman, Sanford (1981). "The Informational Role of Warranties and Private Disclosure about Product Quality," Journal of Law and Economics 24(3): 461-483.

[28] Hao, Lingxin, V. Joseph Hotz and Ginger Zin (2008). "Games Parents and Adolescents Play: Risky Behaviour, Parental Reputation and Strategic Transfers," The Economic Journal 118(528): 515-555.

[29] Hastings, Justine S. and Jeffrey M. Weinstein (2008). "Information, School Choice, and Academic Achievement: Evidence from two Experiments" Quarterly Journal of Economics, vol 123(4) 1373-1414.

[30] Heckman, James J. and Rodrigo Pinto (2013). "Econometric Mediation Analyses: Identifying the Sources of Treatment Effects from Experimentally Estimated Production Technologies with Unmeasured and Mismeasured Inputs," NBER Working Paper No. 19314.

[31] Heckman, James, Rodrigo Pinto and Peter Savelyev (2013). "Understanding the Mechanisms Through Which an Influential Early Childhood Program Boosted Adult Outcomes," American Economic Review 103(6): 2052-2086.

[32] Houtenville, Andrew J. and Karen Smith Conway (2008), "Parental Effort, School Resources and Student Achievement," Journal of Human Resources, vol 43(2): 437-453.

[33] Imai, Kosuke, Dusting Tingley and Luke Keele (2010). "A General Approach to Causal Mediation Analysis," Psychological Methods 15(4): 309-334.

[34] Jacob, Brian and Lars Lefgren (2008). "Can Principals identify Effective Teachers? Evidence on Subjective Performance Evaluation in Education," Journal of Labor Economics, vol 26(1), 101-136.

[35] Kerr, Margaret and Hakan Stattin (2000). "What Parents Know, How They Know It, and Several Forms of Adolescent Adjustment: Further Support for a Reinterpretation of Monitoring," Developmental Psychology 36(3): 366-380. 
[36] Levitt, Steven D., John A. List, Susanne Neckermann and Sally Sadoff (2011). "The Impact of Short-Term Incentives on Student Perofrmance" Mimeo, University of Chicago, Becker Friedman Institute.

[37] Los Angeles Unified School District (2009). "Memorandum of Understanding Between Los Angeles Unified School District and United Teachers Los Angeles." Retrieved on January 10, 2011, from http://publicschoolchoice.lausd.net/sites/default/files/Los\%20Angeles\%20Pilot\% 20Schools\%20Agreement\%20\%28Signed\%29.pdf.

[38] Los Angeles Unified School District (2011). School Report Cards. Retrieved on January 10, 2011, from http://getreportcard.lausd.net/reportcards/reports.jsp.

[39] Milgrom, Paul (1981). "Good News and Bad News: Representation Theorems and Applications," The Bell Journal of Economics 12(2): 380-391.

[40] Miller, Cynthia, James Riccio and Jared Smith (2009). "A Preliminary Look at Early Educational Results of the Opportunity NYC-Family Rewards Program" MDRC.

[41] Rivkin, Steven G., Eric A. Hanushek and John F. Kain (2005). "Teachers, Schools, and Academic Achievement," Econometrica, vol 73(2), 417-458.

[42] Rockoff, Jonah E., Douglas O. Staiger, Thomas J. Kane and Eric S. Taylor (2010). "Information and Employee Evaluation: Evidence from a Randomized Intervention in Public Schools," NBER Working Paper No. 16240.

[43] Rosenbaum, James E. (1998). "College-for-All: Do Students Understand What College Demands?" Social Pyschology of Education, vol 2(1) 55-80.

[44] SFGate.com (2010). Poll Finds Most Blame Parents for School Woes. Retrieved on January 10, 2011, from http://articles.sfgate.com/2010-12-12/news/25188015_1_parentsunited-responsible-education-student-discipline. 
[45] Shin, Hyun Song (1994). "The Burden of Proof in a Game of Persuasion," Journal of Economic Theory 64(1): 253-264.

[46] Springer, Matthew G., D. Ballou, L. Hamilton, V. Le, J.R. Lockwood, D. McCaffrey, M. Pepper and B. Stecher (2010). "Teacher Pay for Performance: Experimental Evidence from the Project on Incentives in Teacher," Nashville, TN: National Center on Performance Incentives at Vanderbilt University.

[47] Stattin, Hakan and Margaret Kerr (2000). "Parental Monitoring: A Reinterpretation," Child Development, vol 71(4), 1072-1085.

[48] Steinberg, Laurence, Lia O’Brien, Elizabeth Cauffman, Sandra Graham, Jennifer Woolard and Marie Banich (2009). "Age Differences in Future Orientation and Delay Discounting" Child Development, vol 80(1): 28-44.

[49] Time Magazine (2010). TIME Poll Results: Americans' Views on Teacher Tenure, Merit Pay and Other Education Reforms. Retrieved online on January 10, 2011, from http://www.time.com/time/nation/article/0,8599,2016994,00.html\#ixzz1dFb1oSwE.

[50] Todd, Petra and Kenneth I. Wolpin (2007), "The Production of Cognitive Achievement in Children: Home, School and Racial Test Score Gaps," Journal of Human Capital, vol 1(1): 91-136.

[51] Valeri, Linda and Tyler VanderWeele (2013). "Mediation Analysis Allowing for Exposure-Mediator Interactions and Causal Interpretation: Theoretical Assumptions and Implementation With SAS and SPSS Macros" Psychological Methods 18(2): 137-150.

[52] Weinberg, Bruce (2001), "An Incentive Model of the Effect of Parental Income on Children," Journal of Political Economy, vol 109(2): 266-280. 
Figure 1: Timeline

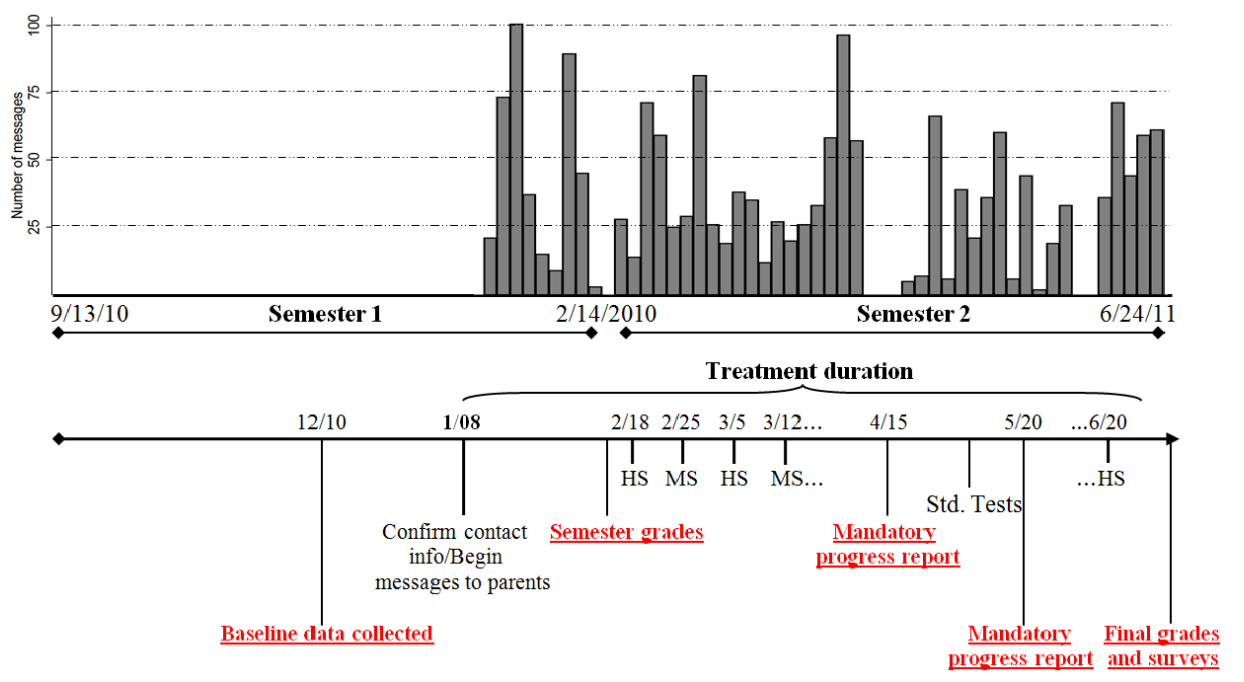

This figure shows the timeline of the experiment. Above the timeline is a chart of the frequency of messages sent to parents. Each bar signifies the number of messages sent over a three-day period and corresponds to the timeline dates below. The abbreviations HS and MS indicate that messages were sent to families of high school (HS) students families on alternate weeks with respect to middle school (MS) students families. "Std. tests" shows when the state-mandated standardized tests took place.

Figure 2: Distribution of baseline GPA

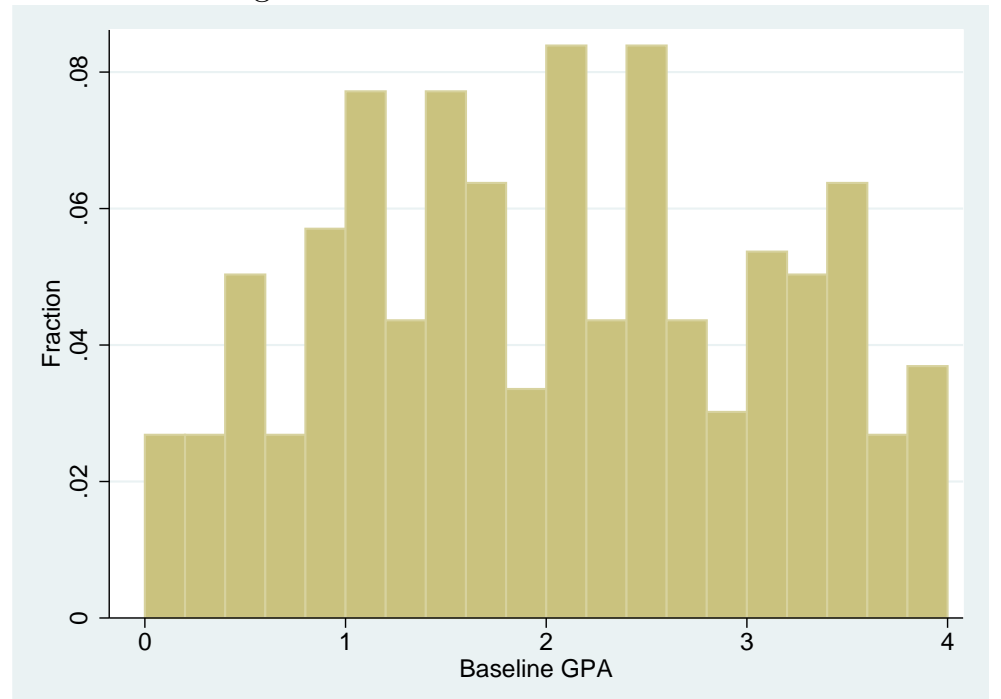

This figure shows the distribution of baseline GPA for all grades. Baseline GPA is calculated from a student's mid-semester progress report, which was two months prior to the start of the treatment. 
Figure 3: Distribution of behaviors at baseline

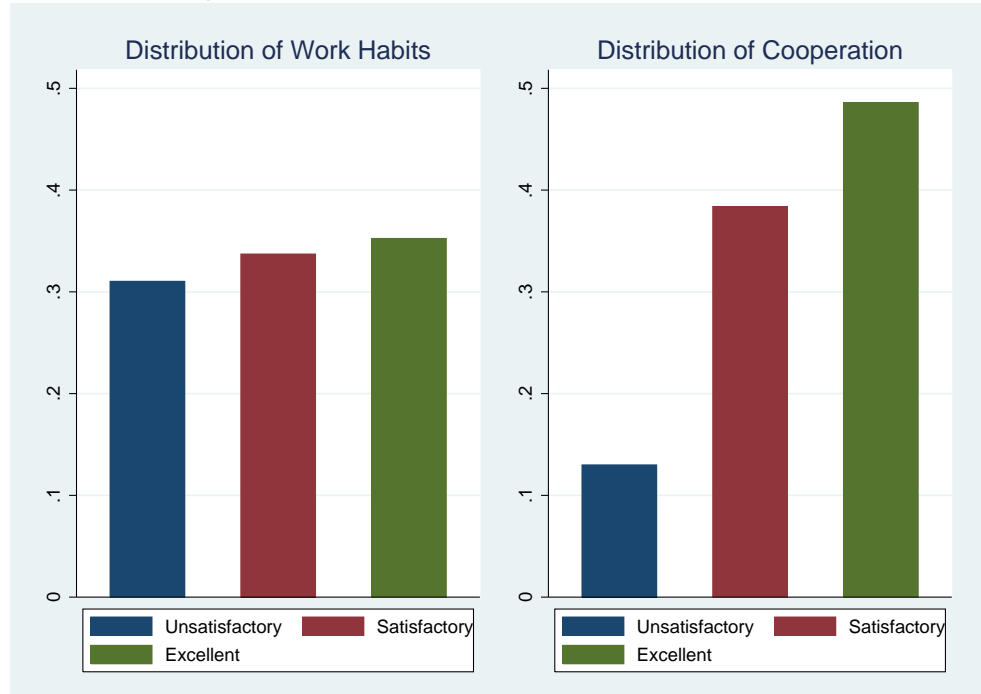

This figure shows the distribution of baseline work habits and cooperation for high school students. Work habits and cooperation are measured as excellent, satisfactory and unsatisfactory. Students receive these marks for each class they take. Several teachers stated that work habits reflect how on task students are during class, while cooperation measures their interactions with the teacher and peers. These measures were drawn from students' mid-semester progress report, which was two months prior to the start of the treatment. 
Figure 4: Parental Beliefs Relative to Truth

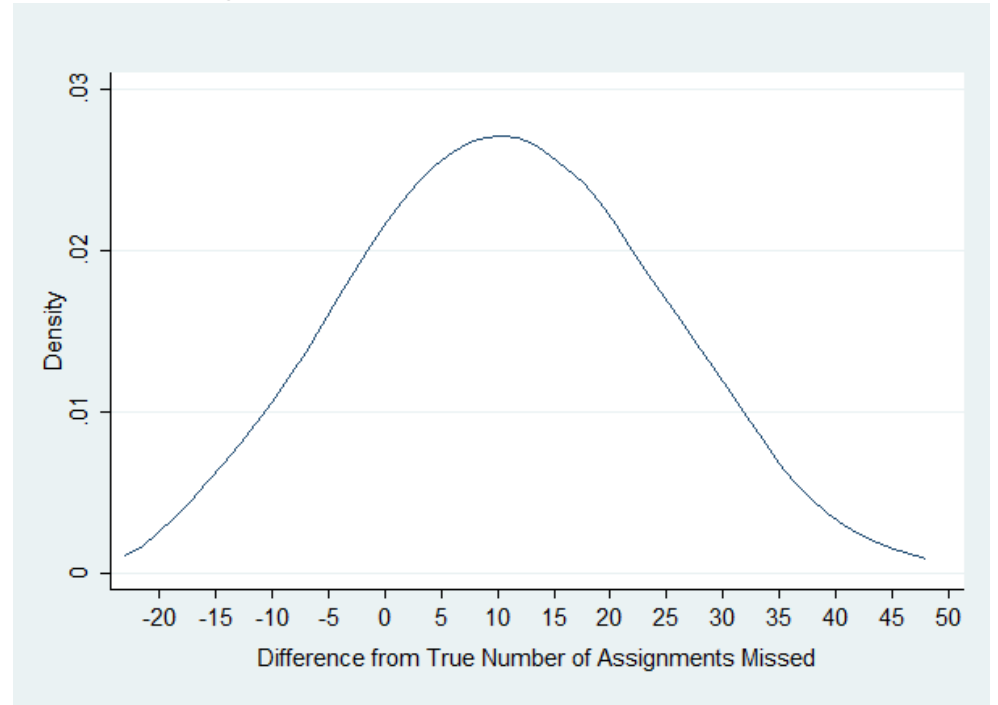

This figure shows a kernel-density plot of the true number of math assignments missed by a student minus the number of missed assignments estimated by parents via survey. Data come from surveys of high school and middle school parents and teacher grade books.

Figure 5: GPA over time for high school students

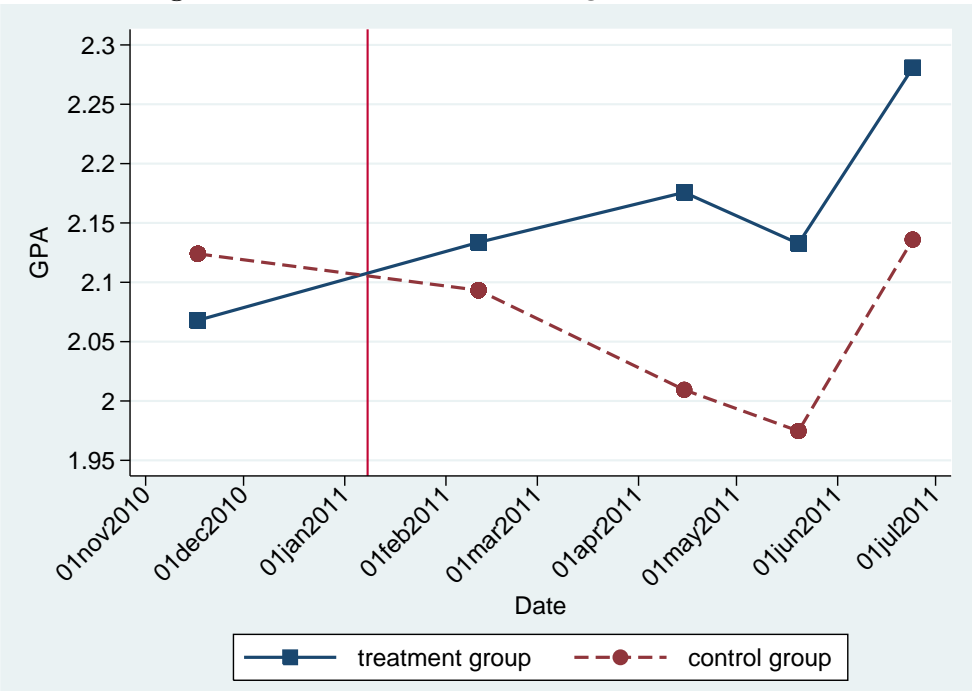

This graph plots the GPA of high school students in the treatment and control group over time. Each point represents the average GPA in a group calculated from progress report grades. The vertical red line indicates when the treatment began. To hold the composition of the sample constant over time, this plot excludes students who left the school prior to the end of the second semester. 
Figure 6: Fraction of work habits marked unsatisfactory over time

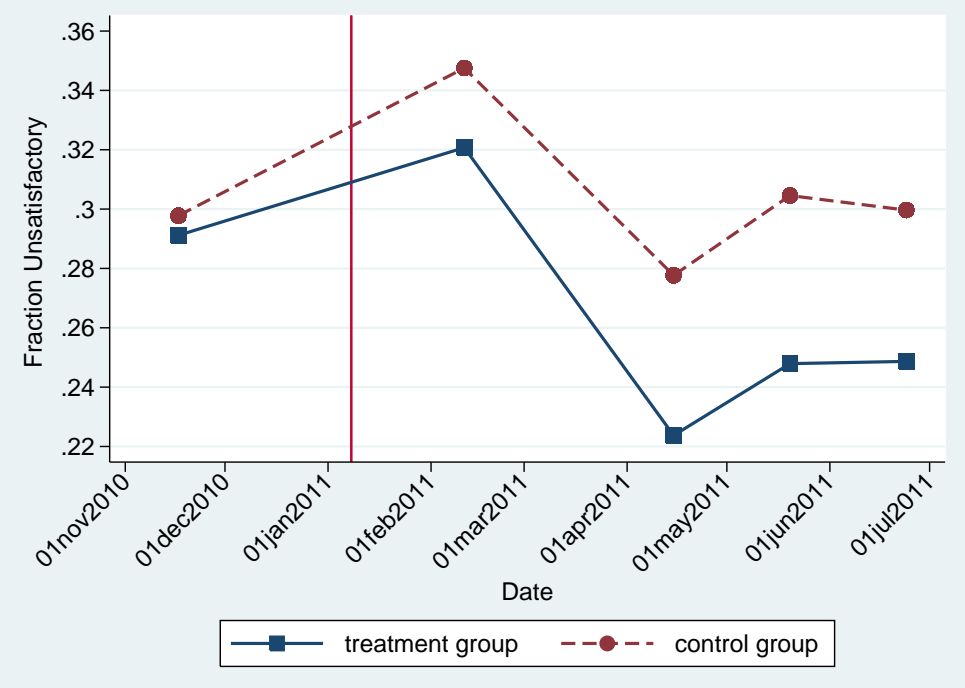

This graph plots the fraction of unsatisfactory work habit marks for the high school treatment and control groups over time. Work habits are graded as either excellent, satisfactory or unsatisfactory. Each point is calculated using progress report marks from each class. The vertical red line indicates when the treatment began. To hold the composition of the sample constant over time, this plot excludes students who left the school prior to the end of the second semester.

Figure 7: Fraction of work habits marked excellent over time

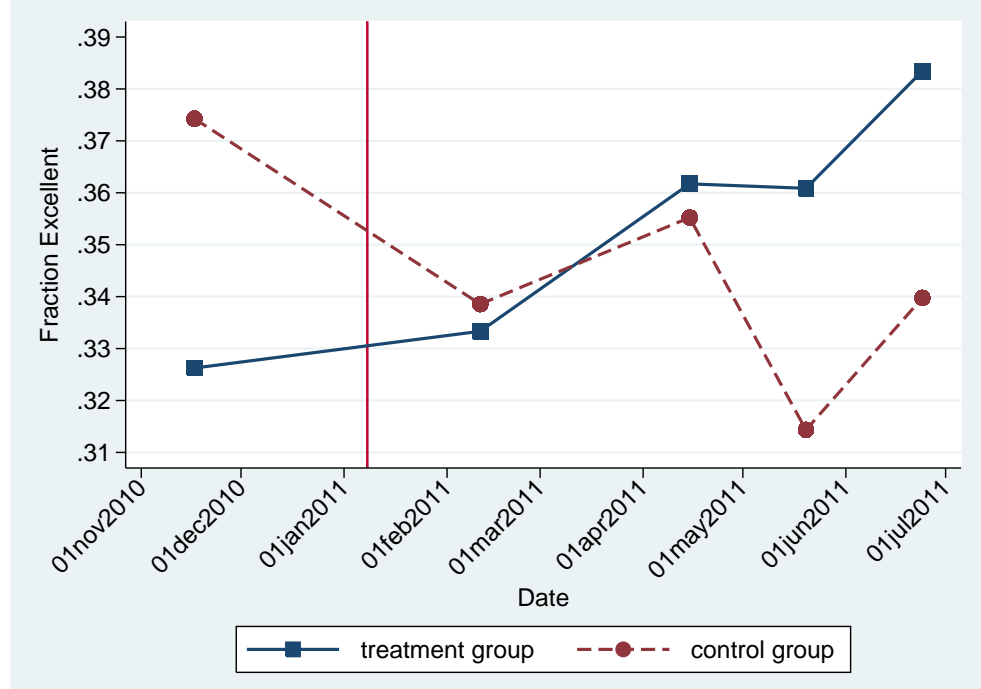

This graph plots the fraction of excellent work habit marks for the high school treatment and control groups over time. Work habits are graded as either excellent, satisfactory or unsatisfactory. Each point is calculated using progress report marks from each class. The vertical red line indicates when the treatment began. To hold the composition of the sample constant over time, this plot excludes students who left the school prior to the end of the second semester. 
Figure 8: Fraction of cooperation marks rated unsatisfactory over time

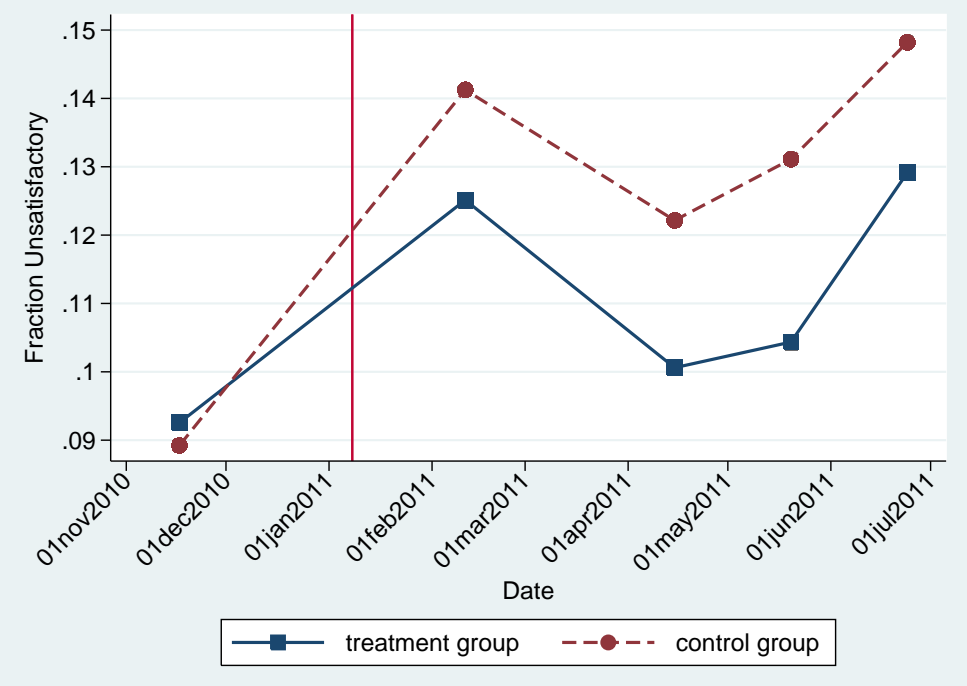

This graph plots the fraction of unsatisfactory cooperation marks for the high school treatment and control groups. Cooperation is graded as either excellent, satisfactory or unsatisfactory. Each point is calculated using progress report marks from each class. The vertical red line indicates when the treatment began. To hold the composition of the sample constant over time, this plot excludes students who left the school prior to the end of the second semester.

Figure 9: Fraction of cooperation marks rated excellent over time

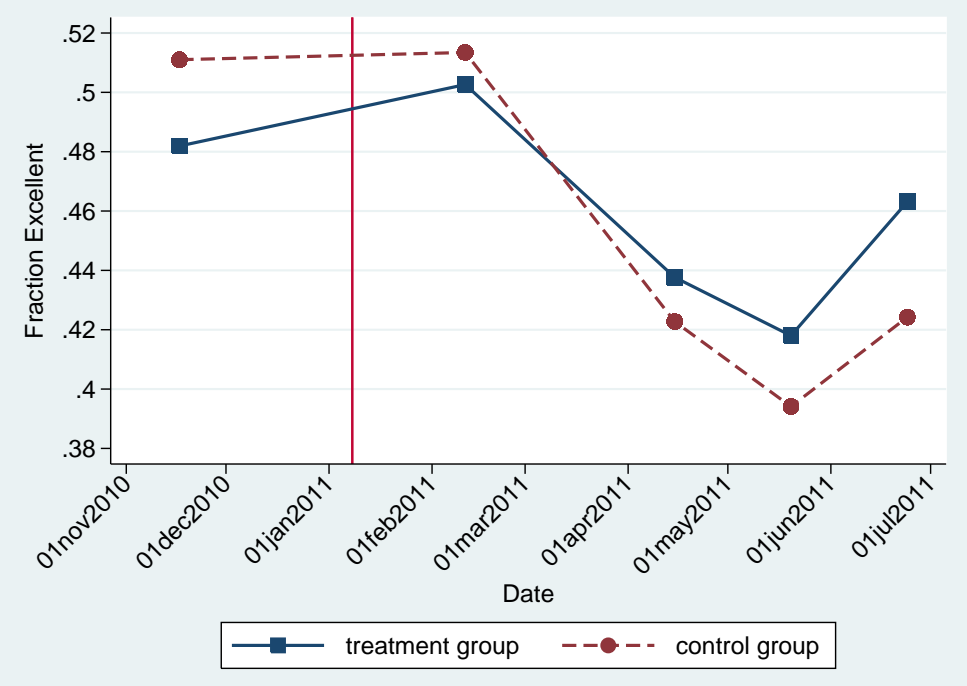

This graph plots the fraction of unsatisfactory cooperation marks for the high school treatment and control groups over time. Cooperation is graded as either excellent, unsatisfactory or excellent. Each point is calculated from progress report marks from each class. The vertical red line indicates when the treatment began. To hold the composition of the sample constant over time, this plot excludes students who left the school prior to the end of the second semester. 
Table 1: Correlations with Parental Beliefs of Student Effort

\begin{tabular}{lcccc}
\hline \hline & $(1)$ & $(2)$ & $(3)$ & $(4)$ \\
Dependent variable & GPA & GPA & GPA & GPA \\
\hline Difference from Truth & $-0.040^{* * *}$ & & & \\
& $(0.007)$ & & & \\
Contacted School & & $-0.031^{*}$ & & \\
& & $(0.016)$ & & \\
Privileges & & & $-0.091^{* * *}$ & \\
& & & $(0.019)$ & \\
Kid does not Disclose & & & & $-0.697^{* * *}$ \\
& & & & $(0.143)$ \\
& 149 & 255 & 256 & 250 \\
\hline Observations & 0.366 & 0.013 & 0.122 & 0.086 \\
R-squared &
\end{tabular}

This table shows associations between parent survey items and student performance. Column (1) shows the correlation of the true number of math assignments missed by a student minus the number of missed assignments estimated by parents with GPA. Sample size varies by response rate. Robust standard errors are in parentheses.

*** $\mathrm{p}<0.01,{ }^{* *} \mathrm{p}<0.05, * \mathrm{p}<0.1$ 
Table 2: Summary Statistics and Treatment-Control Group Balance

\begin{tabular}{|c|c|c|c|c|c|c|}
\hline \multirow[t]{2}{*}{ Panel A. } & \multicolumn{6}{|c|}{ Sample balance including attriters } \\
\hline & $\underline{\text { Control Mean }}$ & $\underline{\text { Treatment Mean }}$ & $\underline{\text { Difference }}$ & $\underline{\mathrm{p} \text {-value }}$ & $\underline{\text { Students }}$ & Obs. \\
\hline Female & 0.363 & 0.463 & 0.099 & 0.078 & 306 & 306 \\
\hline Attendance & 0.928 & 0.942 & 0.014 & 0.278 & 306 & 306 \\
\hline Baseline GPA & 2.019 & 1.995 & -0.024 & 0.848 & 298 & 298 \\
\hline Prior GPA & 2.173 & 2.043 & -0.130 & 0.282 & 252 & 252 \\
\hline Asian & 0.24 & 0.219 & -0.021 & 0.664 & 306 & 306 \\
\hline Black & 0.021 & 0.031 & 0.011 & 0.559 & 306 & 206 \\
\hline Hispanic & 0.699 & 0.725 & 0.026 & 0.612 & 306 & 306 \\
\hline Parent graduated HS & 0.205 & 0.231 & 0.026 & 0.588 & 306 & 306 \\
\hline Free/Reduced Lunch & 0.89 & 0.869 & -0.022 & 0.563 & 306 & 306 \\
\hline Work habits unsatisfactory & 0.326 & 0.308 & -0.019 & 0.585 & 297 & 1953 \\
\hline Cooperation unsatisfactory & 0.111 & 0.105 & 0.006 & 0.751 & 297 & 1952 \\
\hline Work habits excellent & 0.354 & 0.310 & -0.044 & 0.207 & 297 & 1953 \\
\hline Cooperation excellent & 0.487 & 0.458 & -0.029 & 0.385 & 297 & 1952 \\
\hline \multirow[t]{2}{*}{ Panel B. } & \multicolumn{6}{|c|}{ Sample balance excluding attriters } \\
\hline & $\underline{\text { Control Mean }}$ & $\underline{\text { Treatment Mean }}$ & Difference & $\underline{\mathrm{p} \text {-value }}$ & $\underline{\text { Students }}$ & Obs. \\
\hline Female & 0.382 & 0.462 & 0.079 & 0.182 & 279 & 279 \\
\hline Attendance & 0.949 & 0.952 & 0.003 & 0.797 & 279 & 279 \\
\hline Baseline GPA & 2.124 & 2.068 & -0.056 & 0.658 & 272 & 279 \\
\hline Prior GPA & 2.267 & 2.137 & -0.130 & 0.289 & 228 & 228 \\
\hline Asian & 0.243 & 0.238 & -0.005 & 0.924 & 279 & 279 \\
\hline Black & 0.022 & 0.028 & 0.006 & 0.753 & 279 & 279 \\
\hline Hispanic & 0.691 & 0.706 & 0.015 & 0.784 & 279 & 279 \\
\hline Parent graduated HS & 0.213 & 0.238 & 0.025 & 0.626 & 279 & 279 \\
\hline Free/Reduced lunch & 0.904 & 0.888 & -0.016 & 0.657 & 279 & 279 \\
\hline Work habits unsatisfactory & 0.298 & 0.291 & -0.007 & 0.846 & 279 & 1804 \\
\hline Work habits excellent & 0.374 & 0.326 & -0.048 & 0.188 & 279 & 1804 \\
\hline Cooperation unsatisfactory & 0.089 & 0.093 & 0.003 & 0.855 & 279 & 1803 \\
\hline Cooperation excellent & 0.511 & 0.482 & -0.029 & 0.388 & 279 & 1803 \\
\hline
\end{tabular}


Table 3: Contact from the School Regarding Grades

\begin{tabular}{lllll}
\hline \hline & $(1)$ & $(2)$ & $(3)$ & $(4)$ \\
& $\begin{array}{l}\text { School } \\
\text { contact }\end{array}$ & $\begin{array}{l}\text { Contacted } \\
\text { more } \\
\text { than once }\end{array}$ & $\begin{array}{l}\text { School } \\
\text { contact } \\
\text { to parent }\end{array}$ & $\begin{array}{l}\text { Contacted } \\
\text { more } \\
\text { than once }\end{array}$ \\
Dependent variable & to parent & than & & \\
Treatment & $2.125^{* * *}$ & $0.453^{* * *}$ & $1.445^{* * *}$ & $0.308^{* * *}$ \\
& $(0.370)$ & $(0.068)$ & $(0.350)$ & $(0.111)$ \\
Baseline GPA & 0.100 & $-0.105^{* *}$ & -0.191 & -0.074 \\
& $(0.411)$ & $(0.052)$ & $(0.320)$ & $(0.120)$ \\
Prior GPA & -0.125 & $0.100^{*}$ & -0.408 & -0.147 \\
& $(0.341)$ & $(0.051)$ & $(0.420)$ & $(0.123)$ \\
Control mean & 1.134 & 0.286 & 1.360 & 0.448 \\
& & & & \\
\hline Sample & H.S. & H.S. & M.S. & M.S. \\
Observations & 183 & 183 & 80 & 80 \\
R-squared & 0.173 & 0.248 & 0.324 & 0.246 \\
\hline \hline
\end{tabular}

The dependent variable is drawn from surveys of parents. Parents were asked how many times they were contacted by the school regarding their child's grades or schoolwork during the last month of school. Columns (1) and (3) use the number of times contacted by the school as the dependent variable while columns (2) and (4) use an indicator for whether a parent was contacted more than one time. The first two columns are for the high school sample (HS), while the remaining two columns are for the middle school sample (MS), where the experiment was contaminated. Baseline GPA is calculated from students' mid-semester progress reports from two months before the experiment began. Prior GPA is students' cumulative GPA from middle school and beyond. Strata and grade-level indicators are also included in each regression. Robust standard errors are in parentheses.

*** $\mathrm{p}<0.01,{ }^{* *} \mathrm{p}<0.05, * \mathrm{p}<0.1$ 
Table 4: GPA effect on High School Students

\begin{tabular}{lccc}
\hline \hline & $(1)$ & $(2)$ & $(3)$ \\
Dependent variable & GPA & GPA & GPA \\
\hline \multirow{2}{*}{ Treatment } & 0.145 & $0.203^{* *}$ & $0.229^{* *}$ \\
& $(0.143)$ & $(0.093)$ & $(0.090)$ \\
Baseline GPA & & $0.931^{* * *}$ & $0.760^{* * *}$ \\
& & $(0.060)$ & $(0.071)$ \\
Prior GPA & & $0.334^{* * *}$ \\
& & & $(0.072)$ \\
Grade 10 & & & $-0.248^{* *}$ \\
& & & $(0.119)$ \\
Grade 11 & & & -0.164 \\
& & & $(0.117)$ \\
& & 279 & 279 \\
Observations & 279 & 0.601 & 0.645 \\
\hline \hline
\end{tabular}

The dependent variable is students' end-of-semester GPA. Data used in these regressions are from administrative records. Baseline GPA is calculated from students' mid-semester progress reports from two months before the treatment began. Prior GPA is students' cumulative GPA from middle school and beyond. Strata indicators are also included in each regression. High school in this sample includes only grades nine through eleven because the school had just opened. Robust standard errors are in parentheses.

$* * * \mathrm{p}<0.01, * * \mathrm{p}<0.05, * \mathrm{p}<0.1$

Table 5: Effects on Grades

\begin{tabular}{|c|c|c|c|c|c|}
\hline Dependent variable & $\begin{array}{c}(1) \\
\text { Class Grade }\end{array}$ & $\begin{array}{c}(2) \\
\text { Class Grade }\end{array}$ & $\begin{array}{c}(3) \\
\text { Class Grade }\end{array}$ & $\begin{array}{c}(4) \\
\text { Class Grade }\end{array}$ & $\begin{array}{c}(5) \\
\text { Class Grade }\end{array}$ \\
\hline Treatment & $\begin{array}{c}0.231^{* * *} \\
(0.088)\end{array}$ & $\begin{array}{r}0.188^{* *} \\
(0.095)\end{array}$ & $\begin{array}{r}0.208^{* *} \\
(0.089)\end{array}$ & $\begin{array}{l}0.232^{* *} \\
(0.090)\end{array}$ & $\begin{array}{c}0.351^{* * *} \\
(0.135)\end{array}$ \\
\hline Treatment*Target & & $\begin{array}{c}0.120 \\
(0.086)\end{array}$ & & & \\
\hline Treatment*Math class & & & $\begin{array}{c}0.212 \\
(0.132)\end{array}$ & & \\
\hline Treatment*English class & & & & $\begin{array}{c}0.022 \\
(0.119)\end{array}$ & \\
\hline Treatment*Help & & & & & $\begin{array}{l}-0.204 \\
(0.175)\end{array}$ \\
\hline Students & 279 & 279 & 279 & 279 & 279 \\
\hline Observations & 2,224 & 2,224 & 2,224 & 2,224 & 2,224 \\
\hline R-squared & 0.399 & 0.438 & 0.417 & 0.405 & 0.400 \\
\hline
\end{tabular}

The dependent variable in these regressions is each students' class grade, which is coded into a four-point scale from their letter grades. Data used in these regressions are from administrative records. Each student typically takes eight classes. Grades marked incomplete are coded as missing. Additional controls in each regression are students' baseline GPA, prior GPA, grade-level indicators and strata indicators. Baseline GPA is calculated from students' mid-semester progress reports from two months before the treatment began. Prior GPA is students' cumulative GPA from middle school and beyond. Standard errors clustered by student are in parentheses.

$* * * \mathrm{p}<0.01, * * \mathrm{p}<0.05, * \mathrm{p}<0.1$ 


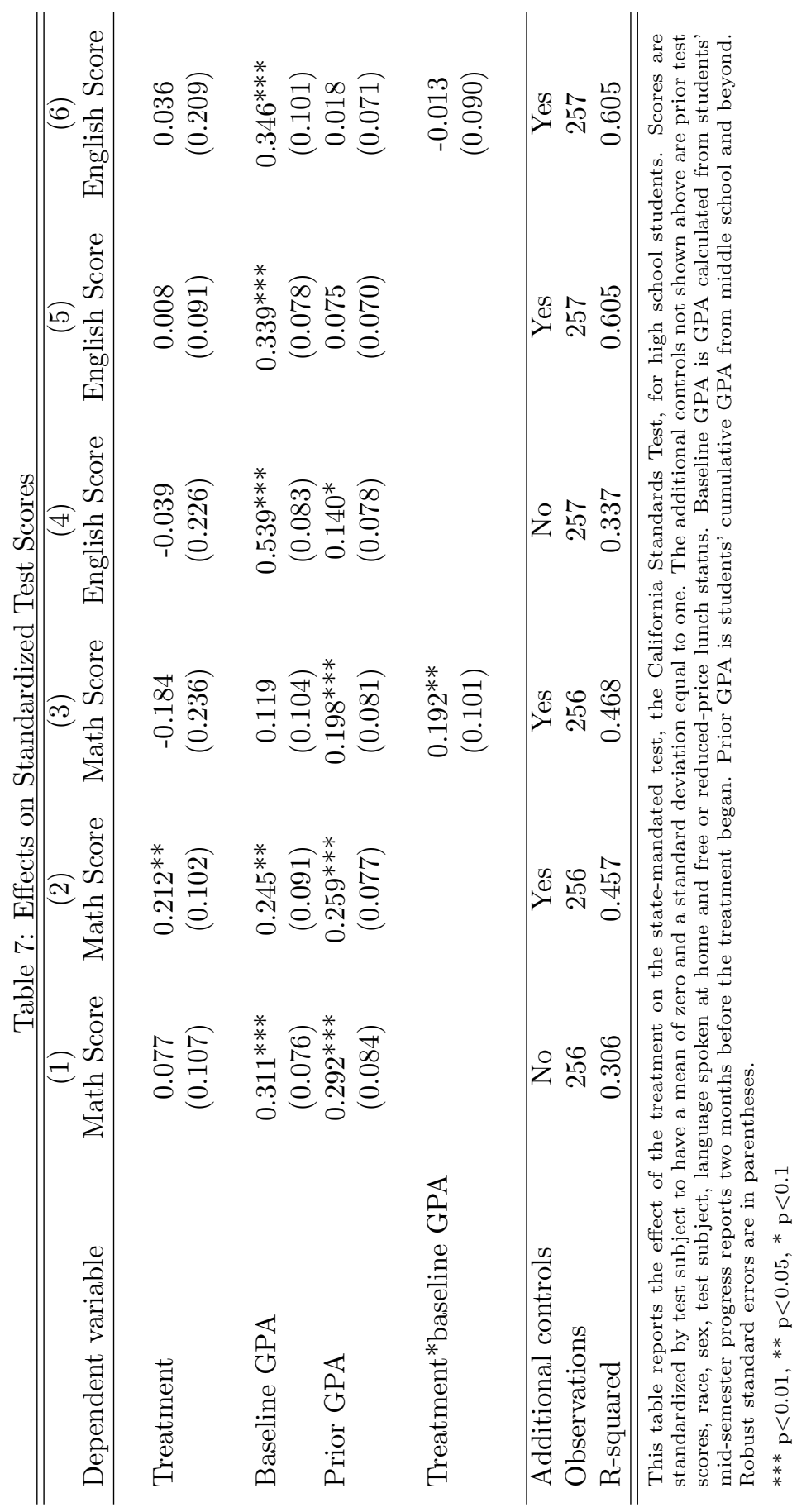


Table 8: Impact of Information on Parental Beliefs

\begin{tabular}{|c|c|c|c|c|}
\hline \multirow{2}{*}{$\begin{array}{l}\text { Panel A. } \\
\text { Dependent variable }\end{array}$} & \multicolumn{4}{|c|}{ Effect on Parental Beliefs } \\
\hline & $\underline{\operatorname{Pr}(\text { Don't Know })}$ & $\operatorname{Pr}(\operatorname{missed} 0-2)$ & $\operatorname{Pr}(\operatorname{missed} 3-5)$ & $\operatorname{Pr}(\operatorname{missed} 5+)$ \\
\hline Treatment & $\begin{array}{l}-0.130^{* *} \\
(0.062)\end{array}$ & $\begin{array}{l}-0.028 \\
(0.070)\end{array}$ & $\begin{array}{l}0.160^{* *} \\
(0.066)\end{array}$ & $\begin{array}{l}-0.002 \\
(0.045)\end{array}$ \\
\hline Observations & 172 & 172 & 172 & 172 \\
\hline Panel B. & \multicolumn{4}{|c|}{ Effect on Accuracy of Beliefs } \\
\hline Dependent variable & $\begin{array}{l}\text { Difference } \\
\text { from Truth } \\
\end{array}$ & $\begin{array}{l}\text { Difference } \\
\text { from Truth } \\
\end{array}$ & $\begin{array}{l}\text { Kid } \\
\text { Doesn't } \\
\text { Disclose }\end{array}$ & \\
\hline Treatment & $\begin{array}{l}-5.564^{*} \\
(3.022)\end{array}$ & $\begin{array}{l}-15.541^{* *} \\
(7.283)\end{array}$ & $\begin{array}{l}0.195^{* * *} \\
(0.070)\end{array}$ & \\
\hline Treatment*Baseline GPA & & $\begin{array}{l}4.606^{*} \\
(2.421)\end{array}$ & & \\
\hline Control Mean & 14.337 & & 0.210 & \\
\hline Observations & 91 & 91 & 176 & \\
\hline R-squared & 0.485 & 0.512 & 0.160 & \\
\hline
\end{tabular}




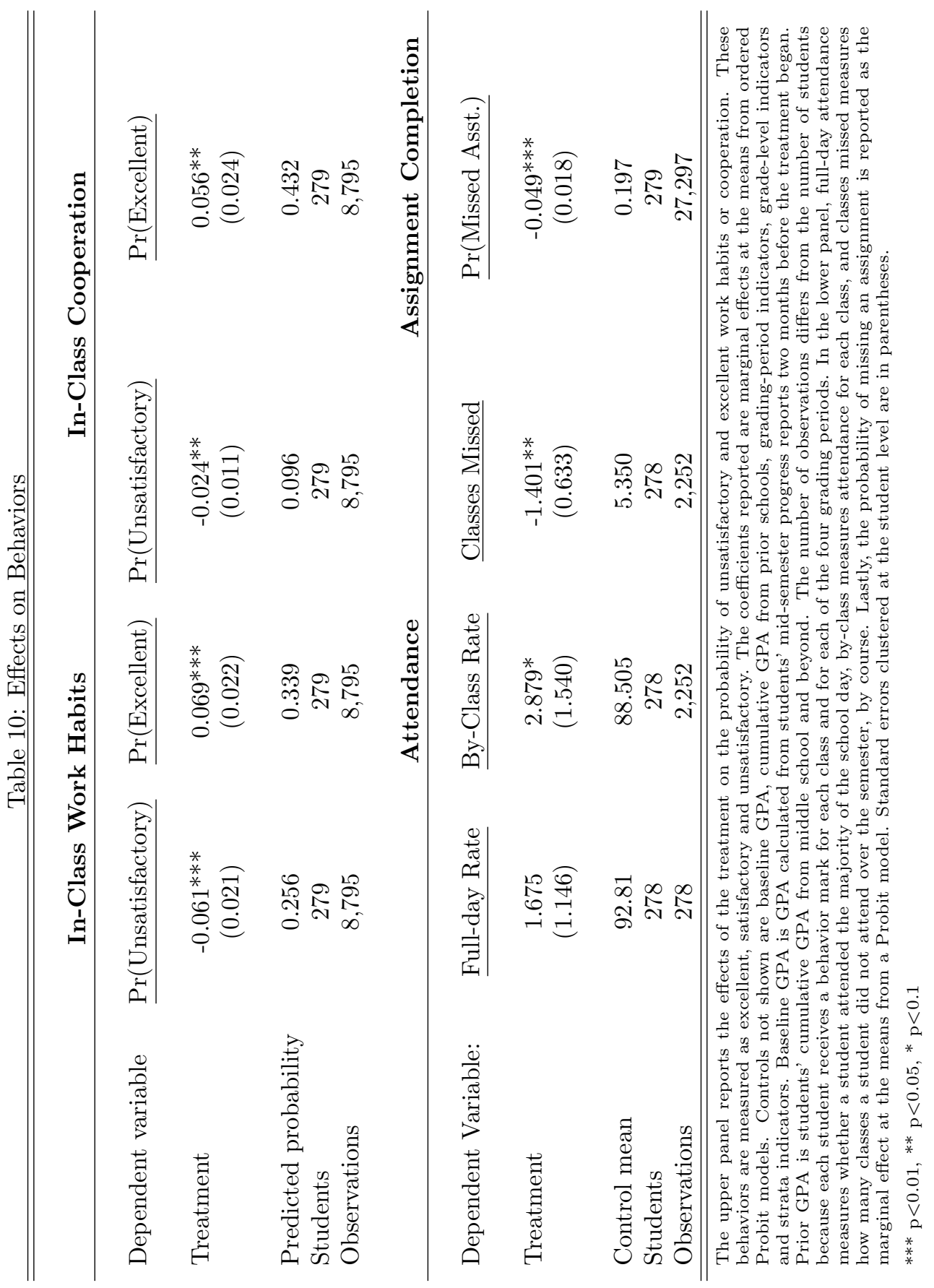


Table 11: Student Responses to Additional Information

\begin{tabular}{|c|c|c|c|c|c|}
\hline \multirow[b]{2}{*}{ Dependent variable } & \multicolumn{5}{|c|}{ How Students Responded Outside of School } \\
\hline & Tutoring & $\begin{array}{l}\text { Homework } \\
\text { last minute }\end{array}$ & Study hours & $\begin{array}{l}\text { Grades } \\
\text { important }\end{array}$ & $\begin{array}{l}\text { College } \\
\text { important }\end{array}$ \\
\hline Treatment & $\begin{array}{l}5.978 \\
(3.763)\end{array}$ & $\begin{array}{c}-0.227^{*} \\
(0.116)\end{array}$ & $\begin{array}{l}0.146 \\
(0.263)\end{array}$ & $\begin{array}{l}0.234^{* *} \\
(0.102)\end{array}$ & $\begin{array}{l}0.040 \\
(0.074)\end{array}$ \\
\hline Control Mean & 14.250 & 1.202 & 0.380 & 3.681 & 3.639 \\
\hline Data source & Child & Child & Child & Child & Child \\
\hline Observations & 154 & 152 & 153 & 155 & 154 \\
\hline R-squared & 0.086 & 0.087 & 0.160 & 0.181 & 0.133 \\
\hline
\end{tabular}

All columns show the effects of the information treatment on parents. Treatment effects are estimated using regressions that control for baseline GPA, prior GPA, strata indicators and grade-level indicators. Baseline GPA is GPA calculated from students' mid-semester progress reports two months before the experiment began. Prior GPA is students' cumulative GPA from middle school and beyond. Data source indicates whether the dependent variable came from a parent's survey response, a child's survey response, or school records. Robust standard errors are in parentheses.

$* * * \mathrm{p}<0.01, * * \mathrm{p}<0.05, * \mathrm{p}<0.1$

Table 12: Effects on GPA Seven Months After Treatment

\begin{tabular}{lcc}
\hline \hline & $(1)$ & $(2)$ \\
Dependent variable & GPA & Grades \\
\hline Treatment & $0.151^{*}$ & $0.174^{* *}$ \\
& $(0.089)$ & $(0.087)$ \\
& & \\
\hline Observations & 241 & 1,863 \\
R-squared & 0.542 & 0.243 \\
\hline \hline
\end{tabular}

This shows the correlation of the true number of math assignments missed by a student minus the number of missed assignments estimated by parents with GPA. Parents who respond "I don't know" are excluded from the sample, though the latter correlates negatively and significantly with GPA as well. Data comes from surveys of parents of high school students. Robust standard errors are in parentheses.

$* * * \mathrm{p}<0.01, * * \mathrm{p}<0.05, * \mathrm{p}<0.1$ 
Table 13: Middle School Student Outcomes

\begin{tabular}{|c|c|c|c|c|}
\hline Dependent Variable & Treatment & Standard Error & Students & Observations \\
\hline GPA & -0.108 & $(0.102)$ & 149 & 149 \\
\hline Final Exams & -0.054 & $(0.199)$ & 87 & 87 \\
\hline Math CST & 0.034 & $(0.119)$ & 139 & 139 \\
\hline English CST & -0.017 & $(0.13)$ & 145 & 145 \\
\hline $\operatorname{Pr}($ missed assignment $)$ & 0.005 & $(0.01)$ & 87 & 7,692 \\
\hline Work habits unsatisfactory & 0.019 & $(0.019)$ & 149 & 2,635 \\
\hline Work habits excellent & -0.041 & $(0.039)$ & 149 & 2,635 \\
\hline Cooperation unsatisfactory & 0.004 & $(0.009)$ & 149 & 2,635 \\
\hline Cooperation excellent & -0.021 & $(0.038)$ & 149 & 2,635 \\
\hline Full-day attendance & -1.101 & $(0.684)$ & 149 & 148 \\
\hline By-class attendance & -1.918 & $(1.24)$ & 149 & 1,933 \\
\hline Classes missed & 0.782 & $(0.49)$ & 149 & 1,933 \\
\hline
\end{tabular}

This table summarizes the results of the treatment effects on middle-school student outcomes, where the experiment was contaminated. The results shown are the coefficients on the treatment indicator in a regression that controls for baseline GPA, prior GPA, grade-level indicators and strata indicators. The treatment effect on missing an assignment is the marginal effect at the means from a Probit model. Work habits and cooperation treatment effects are the marginal effects at the means from an ordered Probit model. All remaining results are estimated by OLS. Where the number of observations differs from the number of students, this is because each student receives a behavior mark for each class as well as each of the four grading periods. By-class attendance is an end-of-semester measure given for each class a student takes. The data for these regressions are drawn from administrative records. Final exam scores could not be obtained for the sixth grade. Standard errors clustered by student are in parentheses.

$* * * \mathrm{p}<0.01, * * \mathrm{p}<0.05, * \mathrm{p}<0.1$ 
Table 14: Middle School Family Survey Outcomes

\begin{tabular}{lrrr}
\hline \hline Dependent Variable & Treatment & Standard Error & N \\
\cline { 1 - 1 } How Parents & Used the Information & \\
& & & \\
Privileges taken last month & 0.260 & $(0.320)$ & 79 \\
Talk about college & -0.548 & $(1.325)$ & 82 \\
Ask about homework & -4.532 & $(2.745)$ & 81 \\
Help with homework & -0.186 & $(0.111)^{*}$ & 65
\end{tabular}

How Students responded

$\begin{array}{lrrr}\text { Tutoring } & 0.845 & (1.500) & 65 \\ \text { HW last minute } & -0.001 & (0.120) & 64 \\ \text { Study hours } & -0.267 & (0.322) & 60 \\ \text { Grades important } & -0.167 & (0.190) & 65 \\ \text { College important } & -0.152 & (0.135) & 65\end{array}$

Information Problems and Information Demand

$\begin{array}{lrrr}\text { Information problem? } & 0.100 & (0.089) & 80 \\ \text { Contacted School } & -0.460 & (0.601) & 81 \\ \text { Can help } & 0.060 & (0.077) & 82\end{array}$

The dependent variables in these OLS regressions are from parent and student surveys. Additional controls in these regressions are baseline GPA, grade-level indicators and strata indicators. These results are for families of middle school students only, where the experiment was contaminated. Robust standard errors are in parentheses.

*** $\mathrm{p}<0.01, * * \mathrm{p}<0.05, * \mathrm{p}<0.1$ 


\section{Appendix for Online Publication}

\section{Tables}

Table A.1: Attrition

\begin{tabular}{|c|c|c|c|c|c|c|}
\hline \multirow{3}{*}{$\begin{array}{l}\text { Dependent variable } \\
\text { Treatment }\end{array}$} & $\overline{(1)}$ & 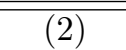 & 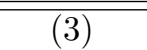 & $\overline{(4)}$ & $\overline{(5)}$ & $\overline{(6)}$ \\
\hline & \multicolumn{6}{|c|}{ Left the Sample } \\
\hline & $\begin{array}{l}-0.016 \\
(0.029)\end{array}$ & $\begin{array}{c}-0.012 \\
(0.026)\end{array}$ & $\begin{array}{c}0.008 \\
(0.018)\end{array}$ & $\begin{array}{c}0.026 \\
(0.031)\end{array}$ & $\begin{array}{c}0.020 \\
(0.031)\end{array}$ & $\begin{array}{c}0.025 \\
(0.027)\end{array}$ \\
\hline 7 th grade & & $\begin{array}{c}0.005 \\
(0.025)\end{array}$ & $\begin{array}{l}-0.032 \\
(0.026)\end{array}$ & & & \\
\hline 8th grade & & $\begin{array}{c}0.061 \\
(0.046)\end{array}$ & $\begin{array}{l}-0.017 \\
(0.027)\end{array}$ & & & \\
\hline Baseline GPA & & & $\begin{array}{l}-0.058 \\
(0.037)\end{array}$ & & & $\begin{array}{l}-0.001 \\
(0.022)\end{array}$ \\
\hline Prior GPA & & & $\begin{array}{c}0.007 \\
(0.036)\end{array}$ & & & $\begin{array}{c}-0.047^{*} \\
(0.027)\end{array}$ \\
\hline Full-day attendance & & & $\begin{array}{c}0.496 \\
(0.306)\end{array}$ & & & $\begin{array}{c}-0.838^{* * *} \\
(0.255)\end{array}$ \\
\hline Female & & & $\begin{array}{l}-0.012 \\
(0.022)\end{array}$ & & & $\begin{array}{l}-0.003 \\
(0.029)\end{array}$ \\
\hline Black & & & $\begin{array}{c}0.937^{* * *} \\
(0.115)\end{array}$ & & & $\begin{array}{c}0.160 \\
(0.121)\end{array}$ \\
\hline Hispanic & & & $\begin{array}{c}-0.160 \\
(0.133)\end{array}$ & & & $\begin{array}{c}0.067 \\
(0.044)\end{array}$ \\
\hline Asian & & & $\begin{array}{l}-0.107 \\
(0.132)\end{array}$ & & & $\begin{array}{c}0.099^{* *} \\
(0.045)\end{array}$ \\
\hline Free/Reduced Lunch & & & $\begin{array}{c}0.027 \\
(0.018)\end{array}$ & & & $\begin{array}{l}-0.026 \\
(0.040)\end{array}$ \\
\hline 10th grade & & & & & $\begin{array}{c}0.089^{* *} \\
(0.041)\end{array}$ & $\begin{array}{c}0.042 \\
(0.034)\end{array}$ \\
\hline 11 th grade & & & & & $\begin{array}{c}0.039 \\
(0.036)\end{array}$ & $\begin{array}{c}0.036 \\
(0.038)\end{array}$ \\
\hline Control mean & 0.041 & & & 0.068 & & \\
\hline Sample & MS & MS & MS & H.S. & H.S. & H.S. \\
\hline Observations & 156 & 156 & 156 & 306 & 306 & 306 \\
\hline R-squared & 0.031 & 0.050 & 0.500 & 0.037 & 0.050 & 0.243 \\
\hline
\end{tabular}

The dependent variable in these regressions is an indicator for having left the school. Columns (1)-(3) show the correlates of leaving for the middle school (MS). Baseline GPA is from mid-semester report cards two months before the treatment began and prior GPA is students' cumulative GPA from previous grades. Columns (4)-(6) show these correlates for the high school (HS) sample only. Robust standard errors are in parentheses.

$* * * \mathrm{p}<0.01,{ }^{* *} \mathrm{p}<0.05,{ }^{*} \mathrm{p}<0.1$ 
Table A.2: Longer-Run Followup Attrition

\begin{tabular}{|c|c|c|c|}
\hline \multirow{3}{*}{$\begin{array}{l}\text { Dependent variable } \\
\text { Treatment }\end{array}$} & $\overline{(1)}$ & $\overline{(2)}$ & $\overline{(3)}$ \\
\hline & \multicolumn{3}{|c|}{ Left the Sample } \\
\hline & \multirow{2}{*}{$\begin{array}{l}-0.022 \\
(0.042)\end{array}$} & \multirow{2}{*}{$\begin{array}{l}-0.022 \\
(0.042)\end{array}$} & $\begin{array}{l}-0.027 \\
(0.040)\end{array}$ \\
\hline Baseline GPA & & & $\begin{array}{l}-0.049 \\
(0.039)\end{array}$ \\
\hline 10th Grade & & $\begin{array}{c}0.146^{* * *} \\
(0.054)\end{array}$ & $\begin{array}{c}0.110^{* *} \\
(0.050)\end{array}$ \\
\hline 11th Grade & & $\begin{array}{c}0.066 \\
(0.051)\end{array}$ & $\begin{array}{c}0.075 \\
(0.047)\end{array}$ \\
\hline Full-day Attendance & & & $\begin{array}{c}-1.168^{* * *} \\
(0.283)\end{array}$ \\
\hline Female & & & $\begin{array}{c}0.024 \\
(0.043)\end{array}$ \\
\hline Black & & & $\begin{array}{l}-0.098 \\
(0.195)\end{array}$ \\
\hline Hispanic & & & $\begin{array}{l}-0.111 \\
(0.139)\end{array}$ \\
\hline Asian & & & $\begin{array}{c}-0.164 \\
(0.138)\end{array}$ \\
\hline Free/Reduced Lunch & & & $\begin{array}{c}-0.235^{* *} \\
(0.094)\end{array}$ \\
\hline Control mean & 0.155 & & \\
\hline Observations & 279 & 279 & 279 \\
\hline R-squared & 0.015 & 0.044 & 0.217 \\
\hline \multicolumn{4}{|c|}{$\begin{array}{l}\text { The dependent variable in these regressions is an indicator for hav- } \\
\text { ing left the school. Columns }(1)-(3) \text { show the correlates of leaving } \\
\text { for the high school school after the conclusion of the treatment. } \\
\text { Baseline GPA is from mid-semester report cards two months before } \\
\text { the treatment began and prior GPA is students' cumulative GPA } \\
\text { from previous grades. Robust standard errors are in parentheses. }\end{array}$} \\
\hline${ }^{* * *} \mathrm{p}<0.01, * * \mathrm{p}<0.05, *$ & & & \\
\hline
\end{tabular}


Table A.3: Survey Response Correlates

\begin{tabular}{|c|c|c|c|c|c|c|}
\hline \multirow[b]{2}{*}{ Dependent variable } & $\overline{(1)}$ & $\overline{(2)}$ & $\begin{array}{l}(3) \\
\end{array}$ & 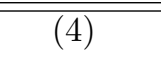 & 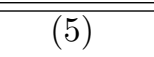 & $\overline{(6)}$ \\
\hline & \multicolumn{6}{|c|}{ Responded to Survey } \\
\hline Treatment & $\begin{array}{c}0.043 \\
(0.056)\end{array}$ & $\begin{array}{c}0.033 \\
(0.055)\end{array}$ & $\begin{array}{c}0.036 \\
(0.050)\end{array}$ & $\begin{array}{c}0.026 \\
(0.057)\end{array}$ & $\begin{array}{c}0.013 \\
(0.056)\end{array}$ & $\begin{array}{c}0.015 \\
(0.053)\end{array}$ \\
\hline Baseline GPA & & $\begin{array}{c}-0.067^{* *} \\
(0.029)\end{array}$ & $\begin{array}{c}0.042 \\
(0.030)\end{array}$ & & $\begin{array}{c}-0.062^{* *} \\
(0.030)\end{array}$ & $\begin{array}{c}0.031 \\
(0.032)\end{array}$ \\
\hline 9 th grade & & $\begin{array}{c}0.219^{* * *} \\
(0.069)\end{array}$ & $\begin{array}{c}0.224^{* * *} \\
(0.062)\end{array}$ & & $\begin{array}{l}0.122^{*} \\
(0.071)\end{array}$ & $\begin{array}{l}0.129^{*} \\
(0.066)\end{array}$ \\
\hline 10th grade & & $\begin{array}{c}0.100 \\
(0.074)\end{array}$ & $\begin{array}{c}0.089 \\
(0.067)\end{array}$ & & $\begin{array}{c}0.056 \\
(0.076)\end{array}$ & $\begin{array}{c}0.046 \\
(0.070)\end{array}$ \\
\hline Full-day attendance & & $\begin{array}{c}0.765^{* * *} \\
(0.265)\end{array}$ & $\begin{array}{c}0.651^{* * *} \\
(0.241)\end{array}$ & & $\begin{array}{c}0.914^{* * *} \\
(0.274)\end{array}$ & $\begin{array}{r}0.809^{* * *} \\
(0.255)\end{array}$ \\
\hline Female & & & $\begin{array}{l}-0.045 \\
(0.052)\end{array}$ & & & $\begin{array}{c}0.000 \\
(0.055)\end{array}$ \\
\hline Hispanic & & & $\begin{array}{c}0.305^{* * *} \\
(0.108)\end{array}$ & & & $\begin{array}{c}0.300^{* * *} \\
(0.114)\end{array}$ \\
\hline Asian & & & $\begin{array}{c}-0.225^{*} \\
(0.115)\end{array}$ & & & $\begin{array}{l}-0.175 \\
(0.121)\end{array}$ \\
\hline Free/Reduced lunch & & & $\begin{array}{c}0.075 \\
(0.059)\end{array}$ & & & $\begin{array}{l}0.108^{*} \\
(0.062)\end{array}$ \\
\hline Control Mean & 0.582 & & & 0.493 & & \\
\hline Sample & Parents & Parents & Parents & Children & Children & Children \\
\hline Observati & 306 & 306 & 306 & 306 & 306 & 306 \\
\hline R-squared & 0.002 & 0.073 & 0.252 & 0.001 & 0.053 & 0.200 \\
\hline
\end{tabular}

The dependent variable in these OLS regressions is an indicator for responding to the survey. Columns (1)-(3) show the correlates of response for the parent survey. Columns (4)-(6) show these correlates for the child survey. The control mean shows the percentage of control-group members who responded to the survey.

These results are for families of high school students only. Robust standard errors are in parentheses.

$* * * \mathrm{p}<0.01, * * \mathrm{p}<0.05, * \mathrm{p}<0.1$ 
Table A.4: Missing CST Scores

\begin{tabular}{lllllll}
\hline \hline & $\begin{array}{l}(1) \\
\text { Missing } \\
\text { math }\end{array}$ & $\begin{array}{l}\text { Missing } \\
\text { math }\end{array}$ & $\begin{array}{l}\text { Missing } \\
\text { math } \\
\text { variable }\end{array}$ & $\begin{array}{l}\text { Missing } \\
\text { English }\end{array}$ & $\begin{array}{l}\text { Missing } \\
\text { English }\end{array}$ & $\begin{array}{l}\text { Missing } \\
\text { English }\end{array}$ \\
\hline Treatment & -0.054 & $-0.060^{*}$ & $-0.065^{*}$ & -0.047 & -0.051 & -0.056 \\
& $(0.033)$ & $(0.033)$ & $(0.035)$ & $(0.032)$ & $(0.032)$ & $(0.035)$ \\
& & & & & $-0.053^{*}$ & -0.050 \\
Baseline GPA & & $-0.050^{*}$ & -0.041 & & $(0.021)$ & $(0.031)$ \\
& & $(0.028)$ & $(0.028)$ & & & \\
Control mean & 0.110 & & & 0.103 & & Yes \\
\hline $\begin{array}{l}\text { Additional } \\
\text { controls }\end{array}$ & No & No & Yes & No & No & \\
$\begin{array}{l}\text { Observations } \\
\text { R-squared }\end{array}$ & 279 & 279 & 279 & 279 & 279 & 279 \\
\hline \hline
\end{tabular}

The dependent variable in these OLS regressions is an indicator for having no test score. Additional controls include prior GPA, prior scores, test-subject indicators and demographic characteristics. Robust standard errors are in parentheses.

$* * * \mathrm{p}<0.01, * * \mathrm{p}<0.05, * \mathrm{p}<0.1$

Table A.5: Sample selection and test scores

\begin{tabular}{lc}
\hline \hline Dependent variable & $(1)$ \\
& GPA \\
Treatment & $0.700^{* *}$ \\
& $(0.356)$ \\
& \\
Treatment*(has score) & -0.546 \\
& $(0.369)$ \\
\hline Observations & 279 \\
R-squared & 0.653 \\
\hline \hline
\end{tabular}

This table shows the treatment effect on GPA, and interacts the treatment variable with an indicator for whether or not a student has a math standardized test score an English standardized test score. These effects are estimated with an OLS regression that controls for baseline GPA, GPA from a students prior school, grade-level indicators and strata indicators. Results are shown for high school students only. All data are from administrative records. Robust standard errors in parentheses.

$* * * \mathrm{p}<0.01, * * \mathrm{p}<0.05, * \mathrm{p}<0.1$ 
Table A.6: Peer Effects

(1)

Dependent variable

Class Grade

Fraction treated

0.578

$(0.500)$

\begin{tabular}{lc}
\hline Observations & 1042 \\
R-squared & 0.417 \\
\hline \hline
\end{tabular}

This table shows how the fraction of the class treated affects class grades for the control group. This effect is calculated using an OLS regression that restricts the sample to the control group and controls for baseline GPA, GPA from a students prior school, grade-level indicators and strata indicators. Results are shown for high school students only. All data are

from administrative records. Standard errors are clustered at the teacher level accounting for the 19 clusters using a Wild bootstrap t (Cameron, Gelbach, Miller, 2008) with 1000 repetitions.

*** $\mathrm{p}<0.01,{ }^{* *} \mathrm{p}<0.05,{ }^{*} \mathrm{p}<0.1$ 


\section{Proofs}

\section{Proposition 1}

The following is the payoff matrix, conditional on type $i$, when there does not exist a report.

$$
\begin{array}{ccc} 
& E, N D & N E, N D \\
M=0 & \left(V-w, w-c_{i}\right) & (-w, w) \\
M=1 & \left(V-w-m, w-c_{i}\right) & (-m, 0)
\end{array}
$$

When a report does exist, payoffs are as follows conditional on type $i$,

$$
\begin{array}{ccccc} 
& E, D & E, N D & N E, D & N E, N D \\
M=0 & \left(V-w, w-c_{i}\right) & \left(V-w, w-c_{i}\right) & (0,0) & (-w, w) \\
M=1 & \left(V-w-m, w-c_{i}\right) & \left(V-w-m, w-c_{i}\right) & (-m, 0) & (-m, 0)
\end{array}
$$

These payoffs show two readily-apparent results. First, parents are strictly worse off by monitoring conditional on child disclosure because they incur monitoring costs and reveal no new information on the child's effort. Thus monitoring will only occur if children do not disclose a verifiable report (and let $m<w$ ). Second, children will not disclose if there exists a report and they exert no effort. Knowing this, consider the child's best responses if $c_{H}<0$, $c_{L}>0$ and $w>0$. Given parents monitor, the child compares $w-c_{i}$ to 0 , which implies high types work and low types work if $c_{L}<w$. However, if both types always work, the parent will have no incentive to monitor, which rules out this equilibrium in pure strategies. If the parent does not monitor, the child compares $w-c_{i}$ to $w$ for working and shirking, respectively. In this case, high types will always work and low types will not work. By comparing 0 to $w$ conditional on shirking for disclosure and no disclosure, respectively, we see low types will not disclose a report while high types are always willing to disclose. This establishes a positive correlation between child disclosure and a child's investment in school.

Given children shirk and do not disclose if they are low type and work if they are high 
type, parents will not monitor conditional on no disclosure if

$$
\pi \geq \frac{w-m}{w-m R}
$$

Thus there is an equilibrium in which high types choose effort and disclosure, low types choose no effort, and parents do not monitor. This occurs if parents believe their child is likely to be of high type, if monitoring costs are high, or if the school infrequently issues a report. Parents will always monitor conditional on no disclosure if

$$
\pi \leq \frac{w-m}{w-m R}
$$

This will be an equilibrium if $c_{L}>w$ because low types will not choose effort in school irrespective of parental monitoring. In pure strategies, only low types do not disclose and parents only monitor if there is no disclosure. This implies a negative correlation between monitoring and student effort.

In terms of mixed strategies, if parents monitor with probability $z$, low-type children are indifferent between effort and no effort if $z=c_{L} / w$. Given the parameters above, high types never mix strategies. If low-type children exert effort with probability $e$, parents are indifferent if

$$
e=\frac{w+m R \pi-m-w \pi}{(1-\pi)(w-m R)}
$$

This equation shows the probability of investing effort in school is decreasing in monitoring costs and parental beliefs. Finally, as the probability of a report increases, so does the probability of investing effort. The above establishes Proposition 1.

\section{Proposition 2}

Define upwardly-biased beliefs as follows. Let the true probability that a child is high type be $\bar{\pi}$. Parents have upwardly-biased beliefs $\hat{\pi}$ if $\hat{\pi}>\bar{\pi}$. In pure strategies, it is not an equilibrium for low-type children to be induced into effort by parental monitoring, as shown 
above, so this proof considers the mixed strategy equilibrium in which high types work and low types randomize effort in school. Consider two parents who have children with true probabilities of being high type equal to $\bar{\pi}$. From equation (1A), we see that

$$
\frac{\partial e}{\partial \pi}=(w-m-(w-m R) \pi)\left(-\frac{1}{(1-\pi)}+\frac{1}{(1-\pi)^{2}(w-m R)}\right) \leq 0
$$

This implies that if one parent has beliefs $\hat{\pi}>\bar{\pi}$, their child will exert less effort. Further, reducing the size of this bias should increase effort. Second,

$$
\frac{\partial e}{\partial m}=(w-m-(w-m R) \pi)\left(\frac{R(1-\pi)}{(1-\pi)(w-m R)^{2}}-\frac{1-R \pi}{(1-\pi)(w-m R)}\right) \leq 0
$$

This shows that effort is decreasing in monitoring costs. A reduction in these costs would increase effort as well. 